\title{
The influence of source-receiver interaction on the numerical prediction of railway induced vibrations
}

\author{
P. Coulier*, G. Lombaert, G. Degrande \\ KU Leuven, Department of Civil Engineering, Kasteelpark Arenberg 40, B-3001 Leuven, Belgium
}

\begin{abstract}
The numerical prediction of vibrations in buildings due to railway traffic is a complicated problem where wave propagation in the soil couples the source (railway tunnel or track) and the receiver (building). This through-soil coupling is often neglected in state-of-the-art numerical models in order to reduce the computational cost. In this paper, the effect of this simplifying assumption on the accuracy of numerical predictions is investigated. A coupled finite element - boundary element methodology is employed to analyze the interaction between a building and a railway tunnel at depth or a ballasted track at the surface of a homogeneous halfspace, respectively. Three different soil types are considered. It is demonstrated that the dynamic axle loads can be calculated with reasonable accuracy using an uncoupled strategy in which through-soil coupling is disregarded. If the transfer functions from source to receiver are considered, however, large local variations in terms of vibration insertion gain are induced by source-receiver interaction, reaching up to $10 \mathrm{~dB}$ and higher, although the overall wave field is only moderately affected. A global quantification of the significance of through-soil coupling is made, based on the mean vibrational energy entering a building. This approach allows assessing the common assumption in seismic engineering that source-receiver interaction can be neglected if the distance between source and receiver is sufficiently large compared to the wavelength of waves in the soil. It is observed that the interaction between a source at depth and a receiver mainly affects the power flow distribution if the distance between source and receiver is smaller than the dilatational wavelength in the soil. Interaction effects for a railway track at grade are observed if the source-receiver distance is smaller than six Rayleigh wavelengths. A similar trend is revealed if the passage of a freight train is considered. The overall influence of dynamic through-soil coupling in terms of power flow remains limited to $2 \mathrm{~dB}$, but the insertion gain at particular locations can easily reach $10 \mathrm{~dB}$. This is of the same order of magnitude as other sources of uncertainty in the numerical prediction of railway induced vibrations; this should hence be accounted for when performing vibration predictions.
\end{abstract}

Keywords: Railway induced vibrations, source-receiver interaction, power flow analysis.

\section{Introduction}

Railway induced vibrations are an important source of annoyance in the built environment. Vibrations in buildings $(1-80 \mathrm{~Hz})$ can disturb sensitive equipment and cause discomfort to people, while re-radiated noise $(16-250 \mathrm{~Hz})$ may be perceived when eigenmodes of floors and walls are excited.

The numerical prediction of railway induced vibrations is a complicated problem, involving various complex physical phenomena such as the generation of dynamic axle loads [1], three-dimensional (3D) wave propagation in the soil and dynamic soil-structure interaction (SSI) $[2,3]$. In the past decades, several numerical models have been developed; the current state-of-the-art includes semi-analytical $[4,5]$, finiteinfinite element [6] and coupled finite element - boundary element (FE-BE) [1,3] models. Computational

\footnotetext{
*Corresponding author. Phone: + 32163216 75. Fax: + 3216321988 .

Email address: pieter.coulier@bwk.kuleuven.be (P. Coulier)
} 
restrictions as well as the lack of knowledge on appropriate model parameters necessitate the introduction of simplifying assumptions in these models. For instance, the assumption of translational invariance or periodicity along the longitudinal direction of a railway tunnel or track is commonly made, allowing for efficient two-and-a-half-dimensional (2.5D) or periodic formulations in the frequency-wavenumber domain $[7,8]$. Furthermore, the soil is usually assumed to be horizontally layered and to behave as a linear elastic isotropic medium, while a perfect contact at the soil-structure interfaces is imposed and the presence of nearby structures is neglected. Some of these assumptions are violated in reality, however, and it is therefore important to investigate to which extent these assumptions affect the accuracy of numerical predictions. Several deviations from standard conditions have been recently considered, such as the effect of an inclined soil stratification [9], soil inhomogeneities [10], non-linear soil behaviour [11], ballast layer solidification [12], the interaction between neighbouring tunnels [13], and the presence of voids at the tunnel-soil interface [14].

In the majority of the numerical models, dynamic SSI at the source (railway tunnel or track) and at the receiver (building) are assumed to be uncoupled, disregarding through-soil coupling of source and receiver. Such an uncoupled approach is well established in seismic engineering, where the distance between source and receiver is sufficiently large compared to the wavelength of waves in the soil, especially in case of far-fault ground motions [15, 16]. Although dynamic through-soil coupling of adjacent structures is receiving increasing attention in the literature (e.g. the interaction of rigid [17, 18] and flexible [19, 20] surface foundations, pile-soil-pile interaction [21] and city site effects [22, 23, 24]), limited attention has been paid so far, however, to source-receiver interaction in the case of railway induced vibrations [25]. Stupazzini and Paolucci [26] present a case where the coupling between an eight-storey building and a surface or underground railway line is taken into account using the spectral element method. In dense urban areas, the distance between source and receiver indeed is of the same order of magnitude as the wavelength in the soil in the frequency range of interest. An example is the recently constructed HSTtunnel in Antwerp (Belgium) which, at certain locations, is situated at a distance of only $4 \mathrm{~m}$ from building foundations [27]; in Chengdu (China), a new museum and subway line are planned within a distance of $20 \mathrm{~m}$ [28]. It is likely that through-soil coupling of source and receiver will alter the propagation of waves in these cases; the validity of uncoupled numerical models therefore requires further investigation.

The aim of this paper is hence to quantify and assess the influence of source-receiver interaction on the numerical prediction of railway induced vibrations. The paper is organized as follows. Section 2 summarizes the governing equations and identifies which variables are possibly affected by source-receiver interaction. Two case studies are subsequently discussed, which are evaluated by means of a 2.5D coupled FE-BE methodology. Section 3 focuses on the interaction between a railway tunnel and a four storey portal frame; three different soil types and two different foundation designs are considered. Both local and global indicators are introduced to characterize the effect of source-receiver interaction on the dynamic axle loads and the transfer functions from tunnel to building. The second case study in section 4 involves a railway track at grade; transfer functions as well as vibrations due to the passage of a freight train are discussed. Concluding remarks are formulated in section 5 .

\section{Numerical prediction of railway induced vibrations}

Figure 1 gives an overview of a general source-receiver interaction problem, involving a railway tunnel and a building. The numerical prediction of railway induced vibrations requires the computation of the response to moving loads, the determination of the dynamic axle loads, and the solution of the dynamic SSI problem for the calculation of the transfer functions from source (tunnel) to receiver (building) [1, 29]. Although the governing equations of each subproblem are well known $[1,29]$, they are summarized in this section to identify quantities of interest that might be affected by source-receiver interaction.

\subsection{Response due to moving loads}

The coupled tunnel-soil-building system shown in figure 1 is subjected to multiple moving loads acting on the rails. In a fixed frame of reference, the body load $\rho \mathbf{b}(\mathbf{x}, t)$ resulting from $n$ axle loads in the vertical 


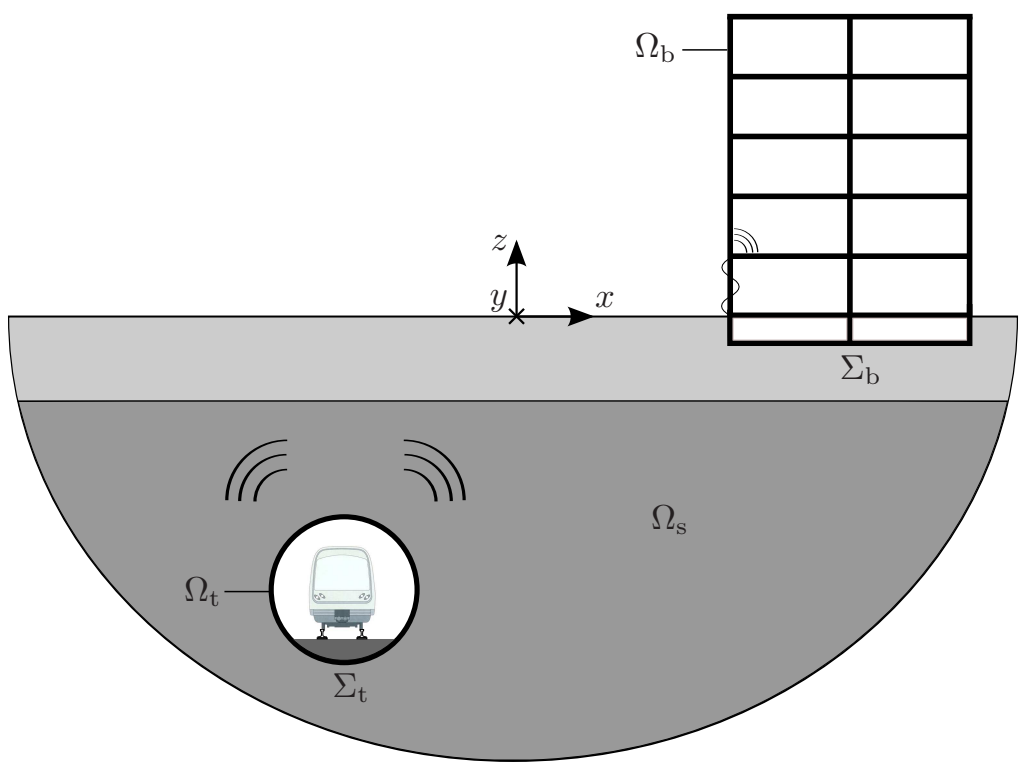

Figure 1: Dynamic soil-structure interaction problem, coupling the source $\Omega_{\mathrm{t}}$ (tunnel) and receiver $\Omega_{\mathrm{b}}$ (building) through wave propagation in the soil domain $\Omega_{\mathrm{s}}$. The soil-structure interfaces are denoted as $\Sigma_{\mathrm{t}}$ and $\Sigma_{\mathrm{b}}$, respectively.

direction $\mathbf{e}_{z}$ and moving at a constant speed $v$ in the direction $\mathbf{e}_{y}$ can be written as [1]:

$$
\rho \mathbf{b}(\mathbf{x}, t)=\sum_{k=1}^{n} \delta\left(x-x_{k 0}\right) \delta\left(y-y_{k 0}-v t\right) \delta\left(z-z_{k 0}\right) g_{k}(t) \mathbf{e}_{z}
$$

where $\mathbf{x}_{k 0}=\left\{x_{k 0}, y_{k 0}, z_{k 0}\right\}^{\mathrm{T}}$ and $g_{k}(t)$ indicate the initial position and the time history of the $k^{\text {th }}$ axle load, respectively. A Fourier transform applied to equation (1) allows to obtain the frequency domain representation $\rho \hat{\mathbf{b}}(\mathbf{x}, \omega)$ of the body load [30], where a hat above a variable denotes its representation in the frequency domain. The vibration response $\hat{u}_{i}(\mathbf{x}, \omega)$ at an arbitrary receiver $\mathbf{x}$ due to the moving loads is calculated as the superposition of the load distribution along the source line and can be formulated as follows [30]:

$$
\hat{u}_{i}(\mathbf{x}, \omega)=\sum_{k=1}^{n} \int_{-\infty}^{+\infty} g_{k}(\tau) \hat{h}_{z i}\left(\mathbf{x}_{k}^{\prime}(\tau), \mathbf{x}, \omega\right) \exp (-i \omega \tau) \mathrm{d} \tau
$$

$\hat{h}_{z i}\left(\mathbf{x}^{\prime}, \mathbf{x}, \omega\right)$ is the transfer function, representing the displacement at a location $\mathbf{x}$ in the direction $\mathbf{e}_{i}$ due to a unit harmonic load applied at a location $\mathbf{x}^{\prime}$ in the direction $\mathbf{e}_{z}$, while $\tau=\left(y^{\prime}-y_{k 0}\right) / v$. Equation (2) indicates that the response due to the moving loads can be calculated from the time history $g_{k}(t)$ of the axle loads and the transfer functions $\hat{h}_{z i}\left(\mathbf{x}^{\prime}, \mathbf{x}, \omega\right)$.

Assuming translational invariance of the geometry in the longitudinal direction $\mathbf{e}_{y}$ allows to write the transfer function $\hat{h}_{z i}\left(x_{k 0}, y_{k 0}+v \tau, z_{k 0}, x, y, z, \omega\right)$ as $\hat{h}_{z i}\left(x_{k 0}, 0, z_{k 0}, x, y-y_{k 0}-v \tau, z, \omega\right)$. Equation (2) can subsequently be simplified using a Fourier transform from the coordinate $y$ to the wavenumber $k_{y}$ [1], resulting in the following expression in the frequency-wavenumber domain [1]:

$$
\tilde{u}_{i}\left(x, k_{y}, z, \omega\right)=\sum_{k=1}^{n} \hat{g}_{k}\left(\omega-k_{y} v\right) \tilde{h}_{z i}\left(x_{k 0}, 0, z_{k 0}, x, k_{y}, z, \omega\right) \exp \left(i k_{y} y_{k 0}\right)
$$

where a tilde above a variable denotes its representation in the frequency-wavenumber domain. Equation (3) clearly illustrates that the response in the frequency-wavenumber domain is the product of the (shifted) frequency spectrum of the axle loads (accounting for the Doppler effect) and the transfer functions. The 
response in the frequency-spatial domain can be found by means of an inverse Fourier from the wavenumber $k_{y}$ to the longitudinal coordinate $y$, using an efficient Filon quadrature scheme [31].

\subsection{Axle loads}

Random excitation due to rail and wheel roughness is one of the main excitation mechanisms giving rise to dynamic forces on the track [32]. The dynamic axle loads $\hat{\mathbf{g}}(\omega)$ originating from the unevenness $\hat{\mathbf{u}}_{\mathrm{w} / \mathrm{r}}(\omega)$ experienced by the vehicle at the vehicle-rail contact points can be calculated in the frequency domain using a compliance formulation in a moving frame of reference, based on the vehicle and track compliance matrices $\hat{\mathbf{C}}^{\mathrm{v}}(\omega)$ and $\hat{\mathbf{C}}^{\operatorname{tr}}(\omega)[1]$ :

$$
\left[\hat{\mathbf{C}}^{\mathrm{v}}(\omega)+\hat{\mathbf{C}}^{\operatorname{tr}}(\omega)\right] \hat{\mathbf{g}}(\omega)=-\hat{\mathbf{u}}_{\mathrm{w} / \mathrm{r}}(\omega)
$$

where the vector $\hat{\mathbf{g}}(\omega)$ collects the $n$ axle loads $\hat{g}_{k}(\omega)$. The vehicle compliance $\hat{\mathbf{C}}^{\mathrm{v}}(\omega)$ is usually computed by modelling the vehicle as a multi-body system, possibly accounting for the wheels, axles, bogies and coaches. Each element $\hat{C}_{i j}^{\mathrm{v}}(\omega)$ of this compliance matrix represents the displacements at the vehicle-rail contact point $i$ due to a unit harmonic load at the contact point $j$. The frequency spectrum of the rail unevenness $\hat{\mathbf{u}}_{\mathrm{w} / \mathrm{r}}(\omega)$ is calculated from the wavenumber representation $\tilde{u}_{\mathrm{w} / \mathrm{r}}\left(k_{y}\right)$ of the unevenness profile $u_{\mathrm{w} / \mathrm{r}}(y)$ and the initial axle positions $\mathbf{x}_{k 0}$. The elements $\hat{C}_{i j}^{\mathrm{tr}}(\omega)$ of the track compliance matrix $\hat{\mathbf{C}}^{\mathrm{tr}}(\omega)$ can be calculated in a moving frame of reference based on the frequency-wavenumber domain transfer function $\tilde{h}_{z z}\left(x_{j}, 0, z_{j}, x_{i}, k_{y}, z_{i}, \omega\right)$, which represent the vertical displacement of the rail due to a unit harmonic vertical load on the rail [1]:

$$
\hat{C}_{i j}^{\operatorname{tr}}\left(\omega-k_{y} v\right)=\frac{1}{2 \pi} \int_{-\infty}^{+\infty} \tilde{h}_{z z}\left(x_{j}, 0, z_{j}, x_{i}, k_{y}, z_{i}, \omega\right) \exp \left(-i k_{y}\left(y_{i}-y_{j}\right)\right) \mathrm{d} k_{y}
$$

In case of a low train speed compared to the critical wave speeds in the tunnel-soil-building system, however, a calculation of the track compliance $\hat{C}_{i j}^{\mathrm{tr}}(\omega)$ in a fixed frame of reference is sufficiently accurate [30]. Equation (5) indicates that the track compliance $\hat{\mathbf{C}}^{\operatorname{tr}}(\omega)$ (and consequently the generation of the dynamic axle loads $\hat{\mathbf{g}}(\omega)$ ) depends on the transfer functions and might hence be affected by source-receiver interaction.

\subsection{Transfer functions}

The calculation of the vibration response $\tilde{u}_{i}\left(x, k_{y}, z, \omega\right)$ at a receiver $\mathbf{x}$ and the determination of the track compliance matrix $\hat{\mathbf{C}}^{\mathrm{tr}}(\omega)$ according to equations (3) and (5), respectively, requires the computation of the transfer functions $\tilde{h}_{z i}\left(x^{\prime}, 0, z^{\prime}, x, k_{y}, z, \omega\right)$. These transfer functions are computed by means of a coupled FE$\mathrm{BE}$ methodology based on a subdomain formulation, accounting for dynamic SSI. The structural domains are modelled by means of finite elements, while boundary elements on the soil-structure interfaces are used to model the soil domain $\Omega_{\mathrm{s}}$ (figure 1). Green's functions for a horizontally layered halfspace are employed as fundamental solutions in the BE formulation [33, 34]. As indicated in subsection 2.1, the translational invariance of the geometry in the longitudinal direction is exploited to formulate the governing equations in the frequency-wavenumber domain, resulting in a computationally efficient 2.5D approach. An extensive discussion of the 2.5D coupled FE-BE methodology can be found in [8]. In the following, the dependence of the displacement on the receiver coordinates $x$ and $z$ and the dependence of the transfer functions on the source coordinates $x^{\prime}$ and $z^{\prime}$ and the receiver coordinates $x$ and $z$ will be omitted for brevity.

If a railway tunnel and building are considered as in figure 1, the governing set of FE-BE equations reads as follows:

$$
\begin{aligned}
\left(\left[\begin{array}{cc}
\tilde{\mathbf{K}}_{\mathrm{t}}\left(k_{y}, \omega\right) & \mathbf{0} \\
\mathbf{0} & \tilde{\mathbf{K}}_{\mathrm{b}}\left(k_{y}, \omega\right)
\end{array}\right]-\omega^{2}\left[\begin{array}{cc}
\mathbf{M}_{\mathrm{t}} & \mathbf{0} \\
\mathbf{0} & \mathbf{M}_{\mathrm{b}}
\end{array}\right]+\left[\begin{array}{cc}
\tilde{\mathbf{K}}_{\mathrm{tt}}^{\mathrm{s}}\left(k_{y}, \omega\right) & \tilde{\mathbf{K}}_{\mathrm{tb}}^{\mathrm{s}}\left(k_{y}, \omega\right) \\
\tilde{\mathbf{K}}_{\mathrm{bt}}^{\mathrm{s}}\left(k_{y}, \omega\right) & \tilde{\mathbf{K}}_{\mathrm{bb}}^{\mathrm{s}}\left(k_{y}, \omega\right)
\end{array}\right]\right)\left\{\begin{array}{c}
\underline{\tilde{\mathbf{u}}}_{\mathrm{t}}\left(k_{y}, \omega\right) \\
\underline{\underline{\mathbf{u}}}_{\mathrm{b}}\left(k_{y}, \omega\right)
\end{array}\right\} & \\
& =\left\{\begin{array}{c}
\underline{\tilde{\mathbf{f}}}_{\mathrm{t}}\left(k_{y}, \omega\right) \\
\underline{0}
\end{array}\right\}
\end{aligned}
$$

$\underline{\tilde{\mathbf{u}}}_{\mathrm{t}}\left(k_{y}, \omega\right)$ and $\underline{\tilde{\mathbf{u}}}_{\mathrm{b}}\left(k_{y}, \omega\right)$ collect the nodal degrees of freedom of the tunnel and the building, while $\tilde{\mathbf{K}}_{\mathrm{t}}\left(k_{y}, \omega\right)$, $\tilde{\mathbf{K}}_{\mathrm{b}}\left(k_{y}, \omega\right), \mathbf{M}_{\mathrm{t}}$ and $\mathbf{M}_{\mathrm{b}}$ represent the finite element stiffness and mass matrices. The matrices $\tilde{\mathbf{K}}_{i j}^{\mathrm{s}}\left(k_{y}, \omega\right)$ 
are dynamic soil stiffness matrices (with indices $i$ and $j$ indicating 't' or ' $\mathrm{b}$ '), with the off-diagonal terms $\tilde{\mathbf{K}}_{\mathrm{tb}}^{\mathrm{s}}\left(k_{y}, \omega\right)$ and $\tilde{\mathbf{K}}_{\mathrm{bt}}^{\mathrm{s}}\left(k_{y}, \omega\right)$ accounting for through-soil coupling of tunnel and building; the force vector $\underline{\tilde{\mathbf{f}}}_{\mathrm{t}}\left(k_{y}, \omega\right)$ results from the external loading on the tunnel. Solving equation (6) allows for the computation of the required transfer functions $\tilde{h}_{z i}\left(k_{y}, \omega\right)$ in the frequency-wavenumber domain.

The dynamic soil stiffness matrices $\tilde{\mathbf{K}}_{i j}\left(k_{y}, \omega\right)$ in equation (6) are calculated by means of the BE method, which is used to evaluate soil tractions $\tilde{\mathbf{t}}_{\mathrm{s}}\left(k_{y}, \omega\right)$ on the soil-structure interface $\Sigma_{i}$ due to imposed displacements on the soil-structure interface $\Sigma_{j}[8]$ :

$$
\tilde{\mathbf{K}}_{i j}\left(k_{y}, \omega\right)=\int_{\Sigma_{i}} \mathbf{N}_{i}^{\mathrm{T}} \mathbf{N}_{i} \tilde{\mathbf{t}}_{\mathbf{s}}\left(\mathbf{N}_{j}\right)\left(k_{y}, \omega\right) \mathrm{d} \Gamma=\int_{\Sigma_{i}} \mathbf{N}_{i}^{\mathrm{T}} \mathbf{N}_{i} \tilde{\mathbf{U}}^{-1}\left(k_{y}, \omega\right)\left[\tilde{\mathbf{T}}\left(k_{y}, \omega\right)+\mathbf{I}\right] \mathbf{N}_{j} \mathrm{~d} \Gamma
$$

where $\mathbf{N}_{i}$ and $\mathbf{N}_{j}$ are shape functions on $\Sigma_{i}$ and $\Sigma_{j} . \tilde{\mathbf{U}}\left(k_{y}, \omega\right)$ and $\tilde{\mathbf{T}}\left(k_{y}, \omega\right)$ are BE system matrices, requiring integration of the Green's displacements and tractions, respectively. The BE model is based on a regularized boundary integral equation which avoids the evaluation of Cauchy principal value (CPV) integrals of the strongly singular Green's tractions [8]. This regularization is based on the fact that the singularity of the static and dynamic fundamental solutions at the source point correspond [35]. In order to mitigate the occurrence of fictitious eigenfrequencies in the application of the BE method to external wave propagation problems, the Combined Helmholtz Integral Equation Formulation (CHIEF) proposed by Schenk [36] is employed.

The collocation matrices $\tilde{\mathbf{U}}\left(k_{y}, \omega\right)$ and $\tilde{\mathbf{T}}\left(k_{y}, \omega\right)$ are fully populated and unsymmetric, however, resulting in stringent memory and CPU requirements: a quadratic amount of memory (with respect to the number of degrees of freedom) is required to store these matrices, while direct numerical solvers require a cubic amount of numerical operations to solve the corresponding set of BE equations. Furthermore, dense unsymmetric dynamic soil stiffness matrices $\tilde{\mathbf{K}}_{i j}^{\mathrm{s}}\left(k_{y}, \omega\right)$ strongly affect the sparsity of the FE-BE system, reducing the efficiency of sparse finite element solvers when applied to equation (6). This indicates that a significant computational effort is needed to assemble and solve the coupled set of equations (6) in order to fully account for through-soil coupling of source and receiver.

It is therefore often preferred to enhance the efficiency of numerical models by disregarding the offdiagonal soil stiffness matrices $\tilde{\mathbf{K}}_{\mathrm{tb}}^{\mathrm{s}}\left(k_{y}, \omega\right)$ and $\tilde{\mathbf{K}}_{\mathrm{bt}}^{\mathrm{s}}\left(k_{y}, \omega\right)$ in the FE-BE equation $(6)$, resulting in an uncoupled two-step approach. In the first step, only the tunnel-soil system is considered and the presence of the building is neglected. The governing set of FE-BE equations hence reads as follows:

$$
\left[\tilde{\mathbf{K}}_{\mathrm{t}}\left(k_{y}, \omega\right)-\omega^{2} \mathbf{M}_{\mathrm{t}}+\tilde{\mathbf{K}}_{\mathrm{t}}^{\mathrm{s}}\left(k_{y}, \omega\right)\right] \underline{\tilde{\mathbf{u}}}_{\mathrm{t}}\left(k_{y}, \omega\right)=\tilde{\tilde{\mathbf{f}}}_{\mathrm{t}}\left(k_{y}, \omega\right)
$$

The dynamic soil stiffness matrix $\tilde{\mathbf{K}}_{\mathrm{t}}^{\mathrm{s}}\left(k_{y}, \omega\right)$ in equation $(8)$ corresponds to $\tilde{\mathbf{K}}_{\mathrm{tt}}^{\mathrm{s}}\left(k_{y}, \omega\right)$ in equation (6). From a computational point of view, however, these matrices slightly differ due to the global regularization procedure employed in the BE method, which involves the rigid body motion of the entire BE mesh [8]. This regularization affects the computation of the weakly singular boundary integrals. As a result, the entries of the $3 \times 3$ block diagonal of the BE matrix $\tilde{\mathbf{T}}\left(k_{y}, \omega\right)$ (and consequently $\tilde{\mathbf{K}}_{\mathrm{t}}^{\mathrm{s}}\left(k_{y}, \omega\right)$ and $\left.\tilde{\mathbf{K}}_{\mathrm{tt}}^{\mathrm{s}}\left(k_{y}, \omega\right)\right)$ are not the same, although the differences are very small. Solving equation (8) provides the tunnel displacements $\underline{\tilde{\mathbf{u}}}_{\mathrm{t}}\left(k_{y}, \omega\right)$. The BE equations allow to retrieve the tractions $\underline{\tilde{\mathbf{t}}}_{\mathrm{t}}\left(k_{y}, \omega\right)$ at the tunnel-soil interface, which are used to evaluate the radiated wavefield in the soil $\underline{\underline{\mathbf{u}}}_{\mathrm{s}}\left(k_{y}, \omega\right)$ through the discretized boundary integral equation [8]:

$$
\underline{\tilde{\mathbf{u}}}_{\mathrm{s}}\left(k_{y}, \omega\right)=\tilde{\mathbf{U}}_{\mathrm{s}}\left(k_{y}, \omega\right) \underline{\tilde{\mathbf{t}}}_{\mathrm{t}}\left(k_{y}, \omega\right)-\tilde{\mathbf{T}}_{\mathrm{s}}\left(k_{y}, \omega\right) \underline{\tilde{\mathbf{u}}}_{\mathrm{t}}\left(k_{y}, \omega\right)
$$

where $\tilde{\mathbf{U}}_{\mathrm{s}}\left(k_{y}, \omega\right)$ and $\tilde{\mathbf{T}}_{\mathrm{s}}\left(k_{y}, \omega\right)$ are BE transfer matrices. The response of the building is subsequently determined in the second step:

$$
\left[\tilde{\mathbf{K}}_{\mathrm{b}}\left(k_{y}, \omega\right)-\omega^{2} \mathbf{M}_{\mathrm{b}}+\tilde{\mathbf{K}}_{\mathrm{b}}^{\mathrm{s}}\left(k_{y}, \omega\right)\right] \underline{\tilde{\mathbf{u}}}_{\mathrm{b}}\left(k_{y}, \omega\right)=\underline{\tilde{\mathbf{f}}}_{\mathrm{b}}^{\mathrm{s}}\left(\underline{\tilde{\mathbf{u}}}_{\mathrm{s}}\right)\left(k_{y}, \omega\right)
$$

The force vector $\underline{\tilde{\mathbf{f}}}_{\mathrm{b}}^{\mathrm{S}}\left(\underline{\tilde{\mathbf{u}}}_{\mathrm{s}}\right)\left(k_{y}, \omega\right)$ denotes the dynamic SSI forces at the building-soil interface $\Sigma_{\mathrm{b}}$ resulting 
from the incident wavefield $\underline{\underline{\tilde{u}}}_{\mathrm{s}}\left(k_{y}, \omega\right)$ :

$$
\underline{\tilde{\mathbf{f}}}_{\mathrm{b}}^{\mathrm{s}}\left(\tilde{\underline{\mathbf{u}}}_{\mathrm{s}}\right)\left(k_{y}, \omega\right)=\int_{\Sigma_{\mathrm{b}}} \mathbf{N}_{\mathrm{b}}^{\mathrm{T}} \mathbf{N}_{\mathrm{b}} \tilde{\mathbf{U}}^{-1}\left(k_{y}, \omega\right) \underline{\tilde{\underline{u}}}_{\mathrm{s}}\left(k_{y}, \omega\right) \mathrm{d} \Gamma
$$

where the BE system matrix $\tilde{\mathbf{U}}\left(k_{y}, \omega\right)$ is determined based on a BE discretization of the interface $\Sigma_{\mathrm{b}}$; only a one-way coupling of source and receiver is provided in this approach. The calculation of a force vector resulting from an incident wavefield by means of the 2.5D FE-BE methodology is discussed in more detail in [37]. Solving equation (10) finally gives the building displacements $\underline{\tilde{\underline{u}}}_{\mathrm{b}}\left(k_{y}, \omega\right)$.

The uncoupled strategy outlined in equations (8)-(10) enables a more efficient solution of the dynamic SSI problem and is therefore generally favoured in numerical models $[1,7]$, both for the determination of the track compliance $\hat{\mathbf{C}}^{\operatorname{tr}}(\omega)$ as well as for the calculation of the transfer functions $\tilde{h}_{z i}\left(k_{y}, \omega\right)$. Through-soil coupling of source and receiver is, however, not rigorously accounted for in this approach. The influence of this approximation on $\hat{\mathbf{C}}^{\operatorname{tr}}(\omega)$ and $\tilde{h}_{z i}\left(k_{y}, \omega\right)$ will be investigated in sections 3 and 4 .

\section{Dynamic interaction between a railway tunnel and a building}

\subsection{Case description}

A case study involving a railway tunnel situated under a building is analyzed in this section. A cross section of the tunnel and the building is shown in figure 2 .

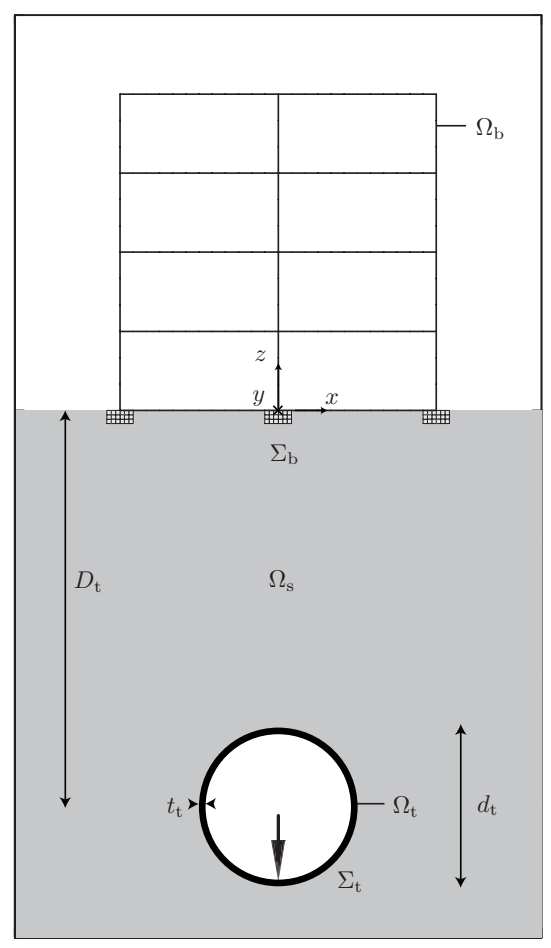

(a)

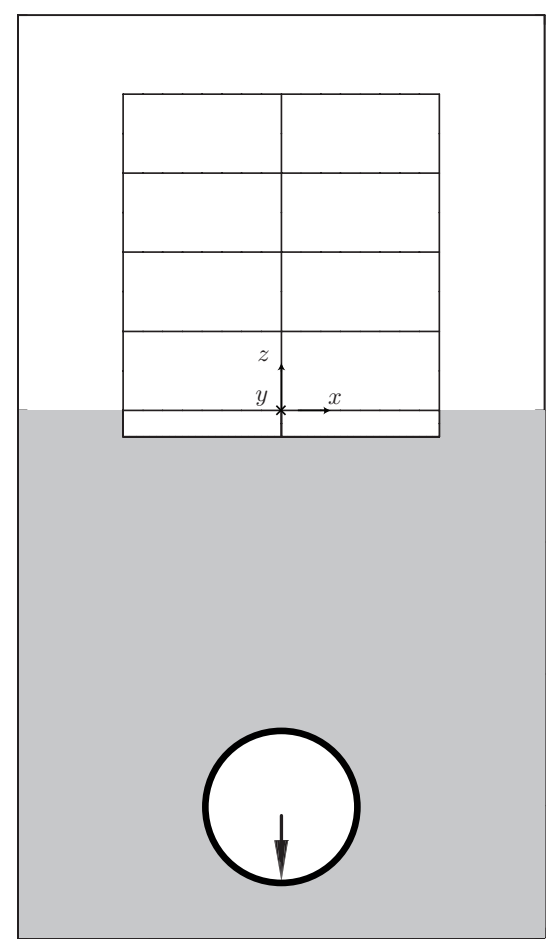

(b)

Figure 2: Railway tunnel $\Omega_{\mathrm{t}}$ situated at a depth $D_{\mathrm{t}}$ below a four storey portal frame $\Omega_{\mathrm{b}}$ founded (a) on three embedded strip foundations and (b) on a box foundation. A unit harmonic vertical point load is applied to the tunnel invert at $\mathbf{x}=$ $\left\{0 \mathrm{~m}, 0 \mathrm{~m},-D_{\mathrm{t}}-d_{\mathrm{t}} / 2+t_{\mathrm{t}}\right\}^{\mathrm{T}}$.

The concrete tunnel has a circular cross section and is embedded in a homogeneous linear elastic halfspace, with its centre situated at a depth $D_{\mathrm{t}}$ below the free surface. The tunnel has an outer diameter $d_{\mathrm{t}}=5.75 \mathrm{~m}$ 
and a wall thickness $t_{\mathrm{t}}=0.25 \mathrm{~m}$. The concrete has a Young's modulus $E_{\mathrm{t}}=50$ GPa, a Poisson's ratio $\nu_{\mathrm{t}}=0.30$, a density $\rho_{\mathrm{t}}=2500 \mathrm{~kg} / \mathrm{m}^{3}$ and a hysteretic material damping ratio $\beta_{\mathrm{t}}=0.025$. There is no track incorporated in the tunnel model. The building is a four storey portal frame (subscript 'pf') consisting of four floors and two spans, with a total width $w_{\mathrm{pf}}=12 \mathrm{~m}$ and a total height $h_{\mathrm{pf}}=12 \mathrm{~m}$. The wall thickness equals $t_{\mathrm{pf}, \mathrm{w}}=0.25 \mathrm{~m}$, while the thickness of the slabs is equal to $t_{\mathrm{pf}, \mathrm{s}}=0.20 \mathrm{~m}$. The walls and slabs are made of reinforced concrete with a Young's modulus $E_{\mathrm{pf}}=30 \mathrm{GPa}$, a Poisson's ratio $\nu_{\mathrm{pf}}=0.30$, a density $\rho_{\mathrm{pf}}=2500 \mathrm{~kg} / \mathrm{m}^{3}$ and a hysteretic material damping ratio $\beta_{\mathrm{pf}}=0.03$. The portal frame is either founded on three embedded strip foundations (figure $2 \mathrm{a}$ ) or on a box foundation (figure $2 \mathrm{~b}$ ). The 2.5D methodology discussed in section 2 is applied for both the tunnel and the building, implying that a building with continuous walls and slabs is modelled. The number of the finite and boundary elements is adjusted to provide ten elements per shear wavelength at the highest frequency of interest $(80 \mathrm{~Hz})$. It has been verified that this suffices to obtain accurate results.

In order to investigate the influence of the soil properties, three different soil types are examined, representing a soft, medium and stiff soil in dry conditions. The dynamic soil characteristics are summarized in table 1.

\begin{tabular}{lccccc}
\hline Type & $\begin{array}{c}C_{\mathrm{s}} \\
{[\mathrm{m} / \mathrm{s}]}\end{array}$ & $\begin{array}{c}C_{\mathrm{p}} \\
{[\mathrm{m} / \mathrm{s}]}\end{array}$ & $\begin{array}{c}\beta_{\mathrm{s}} \\
{[-]}\end{array}$ & $\begin{array}{c}\beta_{\mathrm{p}} \\
{[-]}\end{array}$ & $\begin{array}{c}\rho \\
{\left[\mathrm{kg} / \mathrm{m}^{3}\right]}\end{array}$ \\
\hline Soft & 100 & 200 & 0.03 & 0.03 & 1800 \\
Medium & 200 & 400 & 0.03 & 0.03 & 1800 \\
Stiff & 300 & 600 & 0.03 & 0.03 & 1800 \\
\hline
\end{tabular}

Table 1: Dynamic soil characteristics.

\subsection{Vibration insertion gain}

The interaction of a tunnel embedded in a soft soil (table 1) situated at a depth $D_{\mathrm{t}}=5 \mathrm{~m}$ with a portal frame founded on three embedded strip foundations (figure 2a) is first analyzed. Each of the strip foundations (subscript 'sf') has a width $w_{\mathrm{sf}}=1 \mathrm{~m}$, a height $h_{\mathrm{sf}}=0.5 \mathrm{~m}$ and the following material parameters: $E_{\mathrm{sf}}=$ $33.3 \mathrm{GPa}, \nu_{\mathrm{sf}}=0.20, \rho_{\mathrm{sf}}=2500 \mathrm{~kg} / \mathrm{m}^{3}$ and $\beta_{\mathrm{sf}}=0.03$. Discretization results in $384 \mathrm{FE}$ and $288 \mathrm{BE}$ degrees of freedom (DOFs) for the tunnel as well as $1581 \mathrm{FE}$ and $252 \mathrm{BE}$ DOFs for the building, respectively. All calculations presented in this section have been performed on Intel ${ }^{\circledR}$ Xeon ${ }^{\circledR}$ E5520 $(2.26$ GHz) CPUs. An uncoupled calculation takes $4.1 \mathrm{~h}$ per frequency, while $6.6 \mathrm{~h}$ per frequency is required if source-receiver interaction is accounted for. As the 2.5D equations are solved independently for each wavenumber $k_{y}$ in the frequency-wavenumber domain, the calculations can easily be parallelized. The use of MATLAB's Parallel Computing Toolbox [38] allows for a distributed computation on eight cores, leading to a speed-up by a factor that is slightly less than eight (due to the communication overhead). The actual computation times are hence $32.6 \mathrm{~min}$ and $52.4 \mathrm{~min}$ per frequency for the uncoupled and coupled model, respectively.

Through-soil coupling of source and receiver might affect the track compliance $\hat{\mathbf{C}}^{\text {tr }}(\omega)$ and hence, according to equation (4), the dynamic axle loads $\hat{\mathbf{g}}(\omega)$. Figure 3 shows the vertical tunnel displacement $\hat{u}_{\mathrm{t}}(\mathbf{x}, \omega)$ due to vertical harmonic excitation at $\mathbf{x}=\left\{0 \mathrm{~m}, 0 \mathrm{~m},-D_{\mathrm{t}}-d_{\mathrm{t}} / 2+t_{\mathrm{t}}\right\}^{\mathrm{T}}$ within a frequency range between $0 \mathrm{~Hz}$ and $80 \mathrm{~Hz}$. Both the uncoupled and coupled methodologies outlined in the previous subsection are employed and it is clear that the presence of the building does not significantly modify the result, although small deviations can be observed at low frequencies. This result implies that the track compliance $\hat{\mathbf{C}}^{\operatorname{tr}}(\omega)$ and the dynamic axle loads $\hat{\mathrm{g}}(\omega)$, can be calculated with reasonable accuracy using an uncoupled strategy in which through-soil coupling is disregarded.

Next, the transfer functions from tunnel to building are considered. Figures $4 \mathrm{a}$ and $4 \mathrm{~b}$ show the real part of the vertical displacement $\hat{u}_{z}(\mathbf{x}, \omega)$ at $25 \mathrm{~Hz}$ as obtained with the uncoupled and coupled approach, respectively, due to vertical harmonic excitation of the tunnel at $\left\{0 \mathrm{~m}, 0 \mathrm{~m},-D_{\mathrm{t}}-d_{\mathrm{t}} / 2+t_{\mathrm{t}}\right\}^{\mathrm{T}}$.

A visual comparison of figures $4 \mathrm{a}$ and $4 \mathrm{~b}$ indicates that source-receiver interaction at $25 \mathrm{~Hz}$ modestly affects the displacements in the soil and in the building. The interaction effect can be quantified by means of the vibration insertion gain $\widehat{\mathrm{IG}}_{i}(\mathbf{x}, \omega)$ in the direction $\mathbf{e}_{i}(i=x, y, z)$ at a specific location $\mathbf{x}$ in the soil 

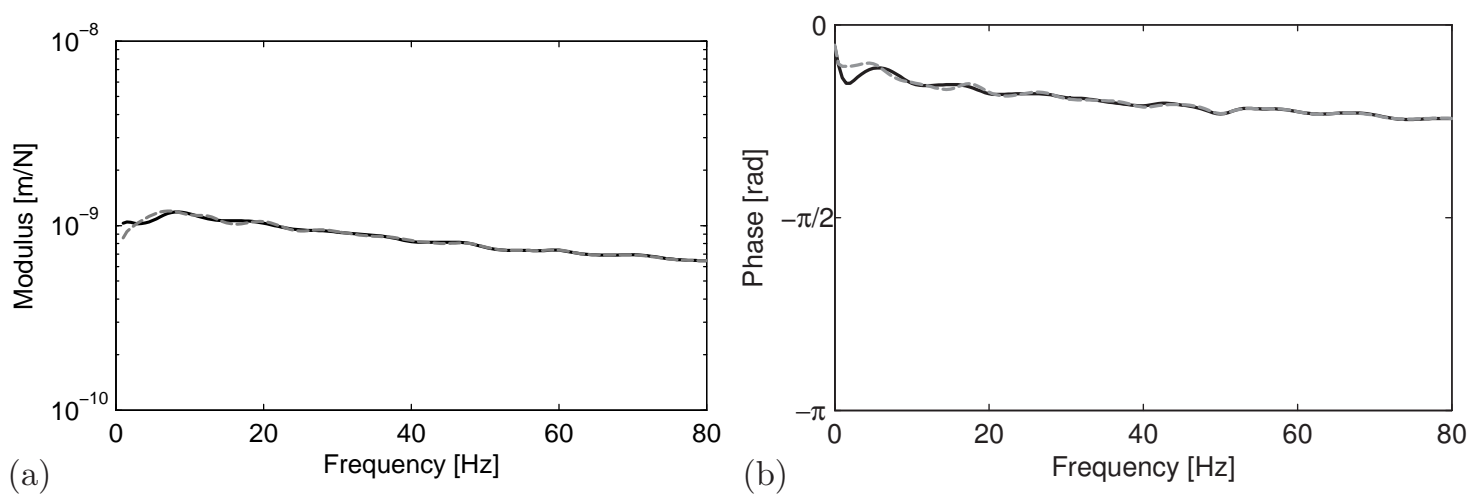

Figure 3: (a) Modulus and (b) phase of the vertical tunnel displacement $\hat{u}_{\mathrm{t}}(\mathbf{x}, \omega)$ due to vertical harmonic excitation in the tunnel at $\mathbf{x}=\left\{0 \mathrm{~m}, 0 \mathrm{~m},-D_{\mathrm{t}}-d_{\mathrm{t}} / 2+t_{\mathrm{t}}\right\}^{\mathrm{T}}$, calculated with the uncoupled (solid black line) and coupled (dashed grey line) approach. The tunnel is embedded in a soft soil and situated at a depth $D_{\mathrm{t}}=5 \mathrm{~m}$ below the free surface.

or in the building, which compares the vibration levels obtained with the uncoupled (superscript ' $u$ ') and coupled (superscript 'c'):

$$
\widehat{\mathrm{IG}}_{i}(\mathbf{x}, \omega)=20 \log _{10} \frac{\left|\hat{u}_{i}^{\mathrm{c}}(\mathbf{x}, \omega)\right|}{\left|\hat{u}_{i}^{\mathrm{u}}(\mathbf{x}, \omega)\right|}
$$

Figure $4 \mathrm{c}$ shows the vertical insertion gain $\widehat{\mathrm{IG}}_{z}(\mathbf{x}, \omega)$ at $25 \mathrm{~Hz}$. The coupling seems to mainly shift the zones of high or low response, resulting in considerable spatial variation of the insertion gain both in the soil and the building, reaching up to $10 \mathrm{~dB}$ and higher. A strong spatial variation is also observed if insertion gains $\widetilde{\mathrm{IG}}_{x}(\mathbf{x}, \omega)$ and $\widehat{\mathrm{IG}}_{y}(\mathbf{x}, \omega)$ are considered, but there is no clear correspondence between these insertion gains at a certain location $\mathbf{x}$.

Figure 5 shows the real part of the vertical displacement $\hat{u}_{z}(\mathbf{x}, \omega)$ as obtained with the uncoupled and coupled approach at a frequency of $75 \mathrm{~Hz}$; a different colour scale is used in comparison with figure 4 . The displacements are very similar in the uncoupled and coupled approach, suggesting that source-receiver interaction is negligible at this frequency. The vertical insertion gain $\widehat{I G}_{z}(\mathbf{x}, \omega)$ is shown in figure 5 c. Although the insertion gain is close to $0 \mathrm{~dB}$ at many locations of the considered spatial domain, large local deviations up to $10 \mathrm{~dB}$ are observed as well, both in the soil and in the building. This can be attributed to the fact that the wave fronts in both approaches are slightly shifted relatively to each other.

Figures $4-5 \mathrm{c}$ indicate that the insertion gain highly depends on the location $\mathbf{x}$. This is illustrated in more detail in figure 6 , in which insertion gains $\widehat{I G}_{i}(\mathbf{x}, \omega)$ are shown as a grey patch for locations $\mathbf{x}$ corresponding to a grid of points located on the first floor of the four storey portal frame, within a range from $y=-10 \mathrm{~m}$ to $y=+10 \mathrm{~m}$. The spatial variability is clearly apparent in this figure; the dependence of the insertion gains on the direction $\mathbf{e}_{i}$ is also demonstrated.

Figures 4-6 reveal that the vibration insertion gain $\widehat{\mathrm{IG}}_{i}(\mathbf{x}, \omega)$ strongly depends on the location $\mathbf{x}$ and the direction $\mathbf{e}_{i}$. A global quantifier which eliminates this dependency is therefore considered as well in this paper. A common approach to evaluate global variations in acoustic measurements or numerical simulations is to compare spatially averaged sound pressure fields in a specific room [39]. Applying a spatial averaging procedure to the source-receiver interaction problem under consideration is, however, less appropriate, as the selection of an averaging area would be rather arbitrary. Furthermore, the dependence on the direction $\mathbf{e}_{i}$ would remain. An alternative power flow approach $[40,41]$ is therefore introduced in the following subsection as a global measure for through-soil coupling of source and receiver.

\subsection{Power flow insertion gain}

The basic principles of power flow analysis are briefly summarized in this subsection. The reader is referred to the literature $[42,43]$ for a detailed description of the methodology. 


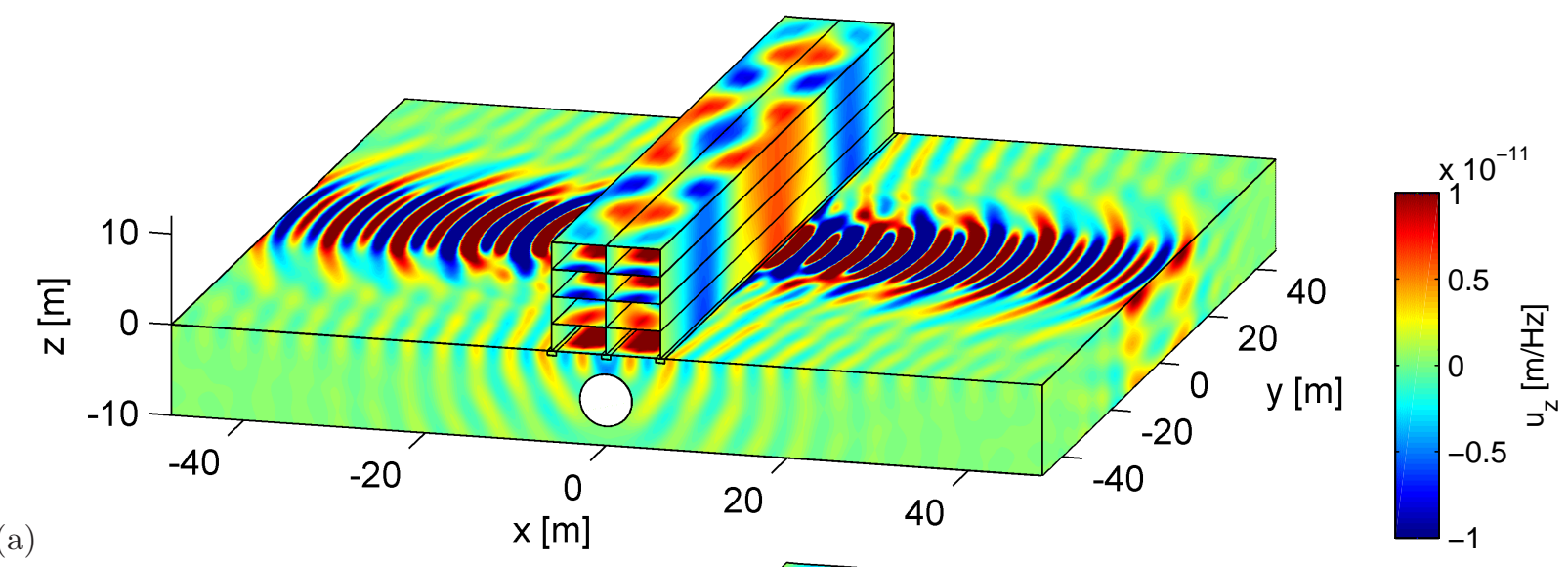

(a)

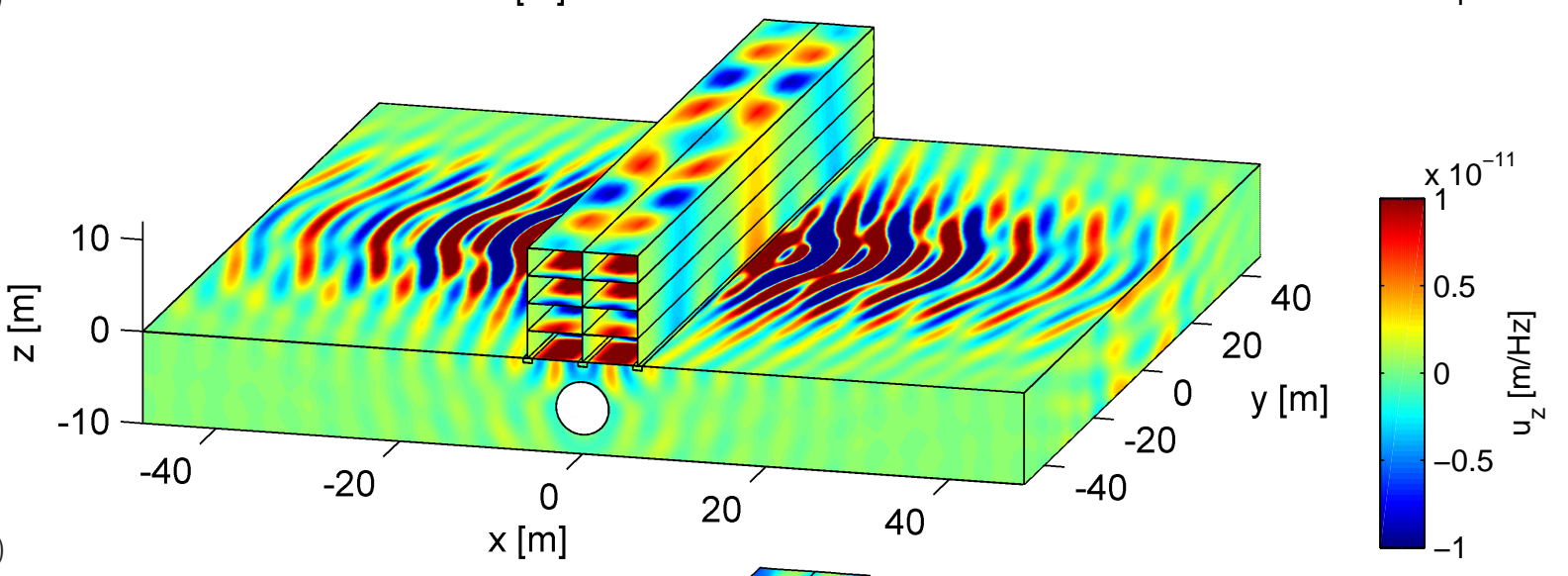

(b)

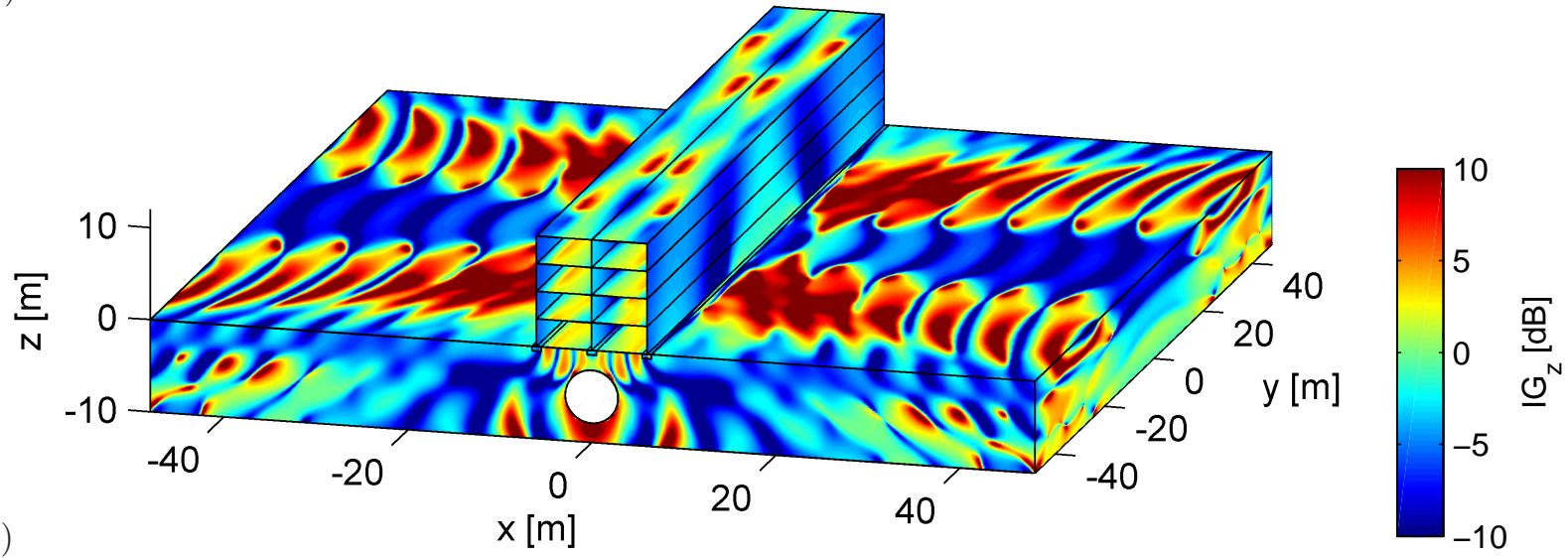

Figure 4: Real part of the vertical soil and building displacement $\hat{u}_{z}(\mathbf{x}, \omega)$ due to vertical harmonic excitation in the tunnel at $\left\{0 \mathrm{~m}, 0 \mathrm{~m},-D_{\mathrm{t}}-d_{\mathrm{t}} / 2+t_{\mathrm{t}}\right\}^{\mathrm{T}}$ at a frequency of $25 \mathrm{~Hz}$ as obtained with (a) the uncoupled and (b) the coupled approach, and (c) the corresponding insertion gain $\widehat{\mathrm{IG}}_{z}(\mathbf{x}, \omega)$. The tunnel is embedded in a soft soil and situated at a depth $D_{\mathrm{t}}=5 \mathrm{~m}$ below the free surface. 


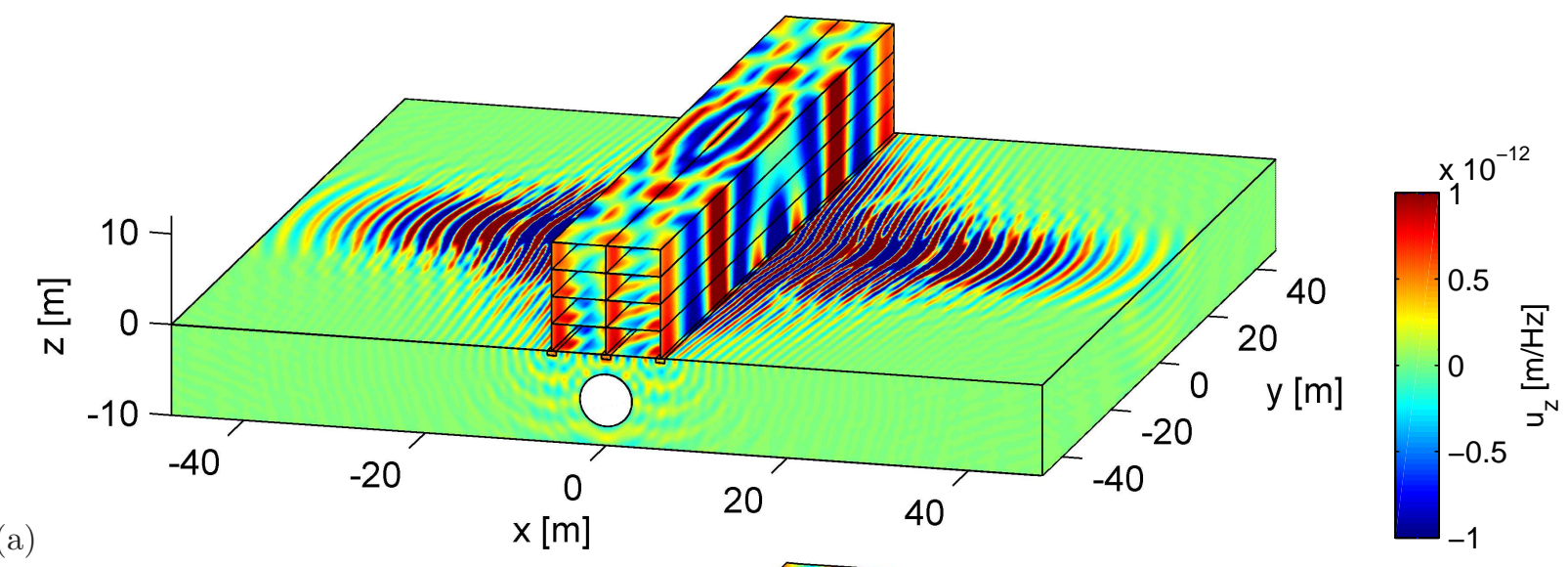

(a)

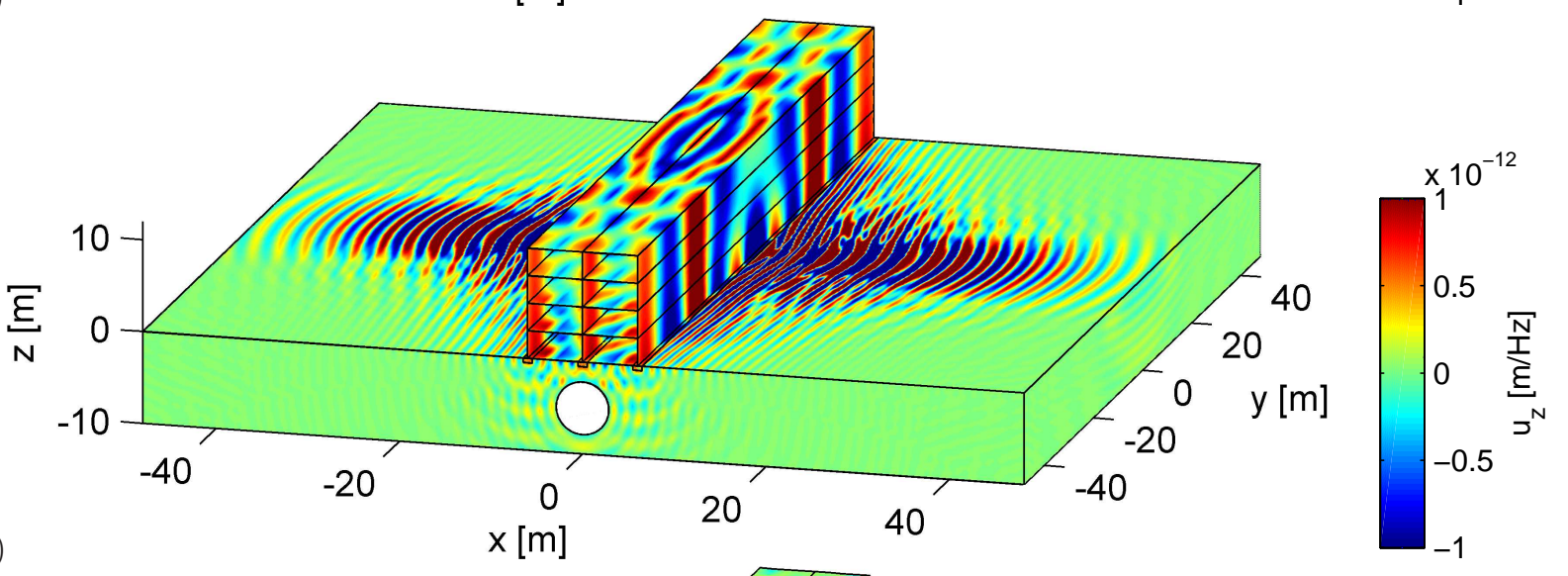

(b)

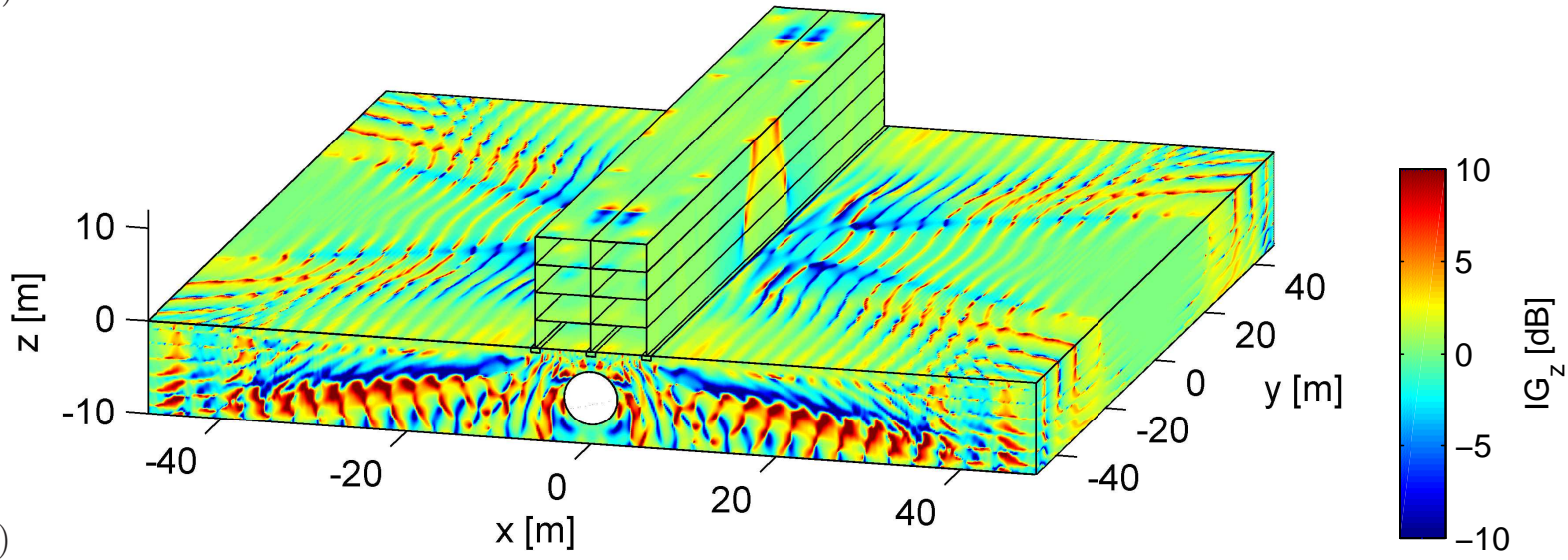

Figure 5: Real part of the vertical soil and building displacement $\hat{u}_{z}(\mathbf{x}, \omega)$ due to vertical harmonic excitation in the tunnel at $\left\{0 \mathrm{~m}, 0 \mathrm{~m},-D_{\mathrm{t}}-d_{\mathrm{t}} / 2+t_{\mathrm{t}}\right\}^{\mathrm{T}}$ at a frequency of $75 \mathrm{~Hz}$ as obtained with (a) the uncoupled and (b) the coupled approach, and (c) the corresponding insertion gain $\widehat{\mathrm{IG}}_{z}(\mathbf{x}, \omega)$. The tunnel is embedded in a soft soil and situated at a depth $D_{\mathrm{t}}=5 \mathrm{~m}$ below the free surface. 

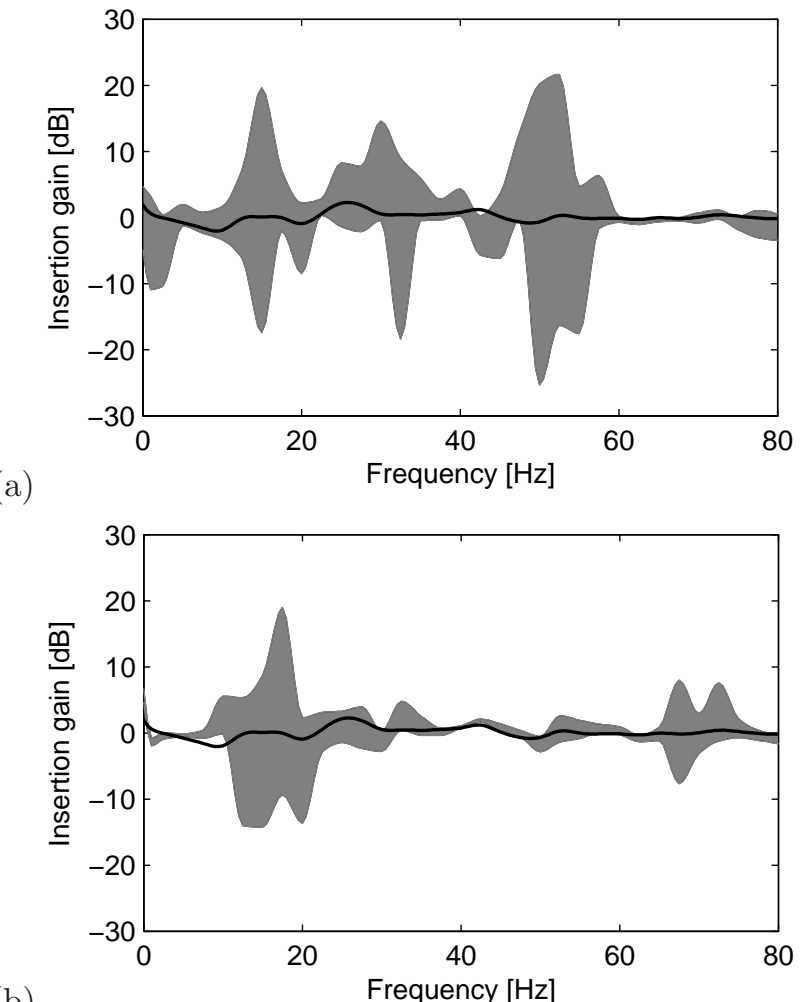

(b)

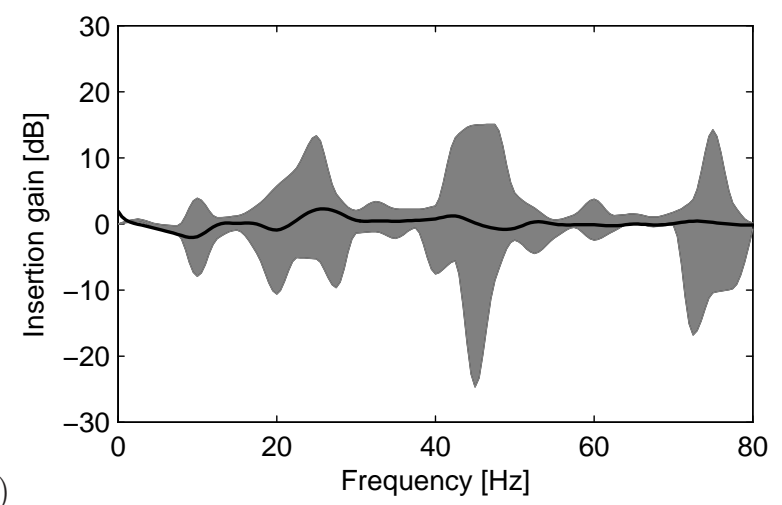

Figure 6: Vibration insertion gains (a) $\widehat{\mathrm{IG}}_{x}(\mathbf{x}, \omega),(\mathrm{b}) \widehat{\mathrm{IG}}_{y}(\mathbf{x}, \omega)$ and (c) $\widehat{\mathrm{IG}}_{z}(\mathbf{x}, \omega)$ on the first floor of the four storey portal frame founded on three embedded strip foundations in a range $y \in[-10 \mathrm{~m}, 10 \mathrm{~m}]$ (grey patch). Superimposed is the power flow insertion gain $\widehat{\mathrm{PFIG}}(\omega)$ (black line). 
Consider an infinitesimal surface $d \Gamma$ through an arbitrary point $Q$ of a continuum $\Omega$, characterized by its unit outward normal vector $\mathbf{n}$ (figure 7 ). Time dependent tractions $\mathbf{t}^{\mathbf{n}}(t)$ are acting on this surface. The

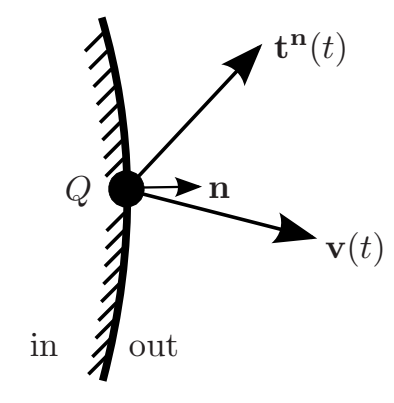

$d \Gamma$

Figure 7: Infinitesimal surface $d \Gamma$ with a unit outward normal $\mathbf{n}$ through an arbitrary point $Q$ of a continuum $\Omega$.

instantaneous power flow $p^{\mathbf{n}}(t)$ through $d \Gamma$ at time $t$ is the rate of work performed by the tractions $\mathbf{t}^{\mathbf{n}}(t)$, defined as the inner product of the traction vector $\mathbf{t}^{\mathbf{n}}(t)$ and the velocity vector $\mathbf{v}(t)[42,43]$ :

$$
p^{\mathbf{n}}(t)=-\mathbf{t}^{\mathbf{n}}(t) \cdot \mathbf{v}(t)
$$

where the velocity vector $\mathbf{v}(t)$ is defined as $\mathbf{v}(t)=\partial \mathbf{u}(t) / \partial t$. A positive inner product of $\mathbf{t}^{\mathbf{n}}(t)$ and $\mathbf{v}(t)$ corresponds to the transmission of energy per unit of time through the surface $d \Gamma$ from the outer to the inner side, as defined in figure 7 [44]; the minus sign in equation (13) thus ensures a positive power flow $p^{\mathbf{n}}(t)$ from the inner to the outer side. The instantaneous power flow can be rewritten by introducing Cauchy's formula in equation (13):

$$
p^{\mathbf{n}}(t)=-(\boldsymbol{\sigma}(t) \cdot \mathbf{n}) \cdot \mathbf{v}(t)=\left(-\boldsymbol{\sigma}^{\mathrm{T}}(t) \cdot \mathbf{v}(t)\right) \cdot \mathbf{n}=\mathbf{p}(t) \cdot \mathbf{n}
$$

where $\mathbf{p}(t)$ represents the instantaneous power flow density vector [44]. Equation (14) allows to determine the power flow through an arbitrary plane characterized by a unit outward normal vector $\mathbf{n}$ from the power flow through three mutually perpendicular planes.

The mean power flow density vector $\langle\hat{\mathbf{p}}(\omega)\rangle$ is the time average of $\mathbf{p}(t)$ over a period of vibration $2 \pi / \omega$ and can be expressed in terms of the complex quantities $\hat{\boldsymbol{\sigma}}(\omega)$ and $\hat{\mathbf{u}}(\omega)$ [42]:

$$
\langle\hat{\mathbf{p}}(\omega)\rangle=-\frac{1}{2} \operatorname{Re}\left(\hat{\boldsymbol{\sigma}}^{\star}(\omega) \cdot \hat{\mathbf{v}}(\omega)\right)=-\frac{1}{2} \operatorname{Re}\left(i \omega \hat{\boldsymbol{\sigma}}^{\star}(\omega) \cdot \hat{\mathbf{u}}(\omega)\right)
$$

where $\star$ indicates the complex conjugate. Equation (15) is valid for a continuum; expressions for the instantaneous and mean power flow density vector in a Timoshenko beam and a thin plate can be found in [45] and [46], respectively. The total mean power flow $\langle\hat{P}(\Gamma, \omega)\rangle$ through a surface $\Gamma$ is finally calculated as:

$$
\langle\hat{P}(\Gamma, \omega)\rangle=\int_{\Gamma}\left\langle\hat{p}^{\mathbf{n}}(\omega)\right\rangle d \Gamma=\int_{\Gamma}\langle\hat{\mathbf{p}}(\omega)\rangle \cdot \mathbf{n} d \Gamma
$$

The power flow concept allows introducing power flow insertion gain $\widehat{\mathrm{PFIG}}(\omega)$ as a global indicator for source-receiver interaction:

$$
\widehat{\operatorname{PFIG}}(\omega)=10 \log _{10} \frac{\left\langle\hat{P}^{\mathrm{c}}\left(\Sigma_{\mathrm{b}}, \omega\right)\right\rangle}{\left\langle\hat{P}^{\mathrm{u}}\left(\Sigma_{\mathrm{b}}, \omega\right)\right\rangle}
$$


where $\left\langle\hat{P}\left(\Sigma_{\mathrm{b}}, \omega\right)\right\rangle$ denotes the total mean power flowing into the building through the soil-building interface $\Sigma_{\mathrm{b}}$ (i.e. through the three soil-foundation interfaces indicated on figure 2). This provides a global measure to characterize the significance of through-soil coupling in numerical models, based on the mean vibrational energy entering a structure driving all internal structural vibrations and re-radiated noise [47]. A change of the amount of power flowing into the building caused by through-soil coupling is thus of main interest for the evaluation of source-receiver interaction. It must be emphasized, however, that the power flow approach is introduced here in order to make a global comparison of results obtained with two numerical methodologies (i.e. coupled vs. uncoupled).

In figure 6 , the $\widehat{\mathrm{PFIG}}(\omega)$ is superimposed on the insertion gains $\widehat{\mathrm{IG}}_{i}(\mathbf{x}, \omega)$. The $\widehat{\mathrm{PFIG}}(\omega)$ varies around $\pm 2 \mathrm{~dB}$ in the lower frequency range, while the influence of source-receiver interaction seems to be negligible at higher frequencies. The spatial and directional variation are removed through this approach, as a single value per frequency is obtained.

Power flow provides additional insight in the physical behaviour, as it allows to identify the dominant vibration transmission paths. Figure 8 shows the mean power flow per unit length through the tunnel-soil interface as a function of the longitudinal coordinate and the frequency, where positive values correspond to the transmission of energy from the tunnel into the soil (cfr. equation (13)). This figure clearly illustrates that the power flow distribution around the tunnel is not affected by the presence of the building in the frequency range of interest, as could be expected from figure 3 .
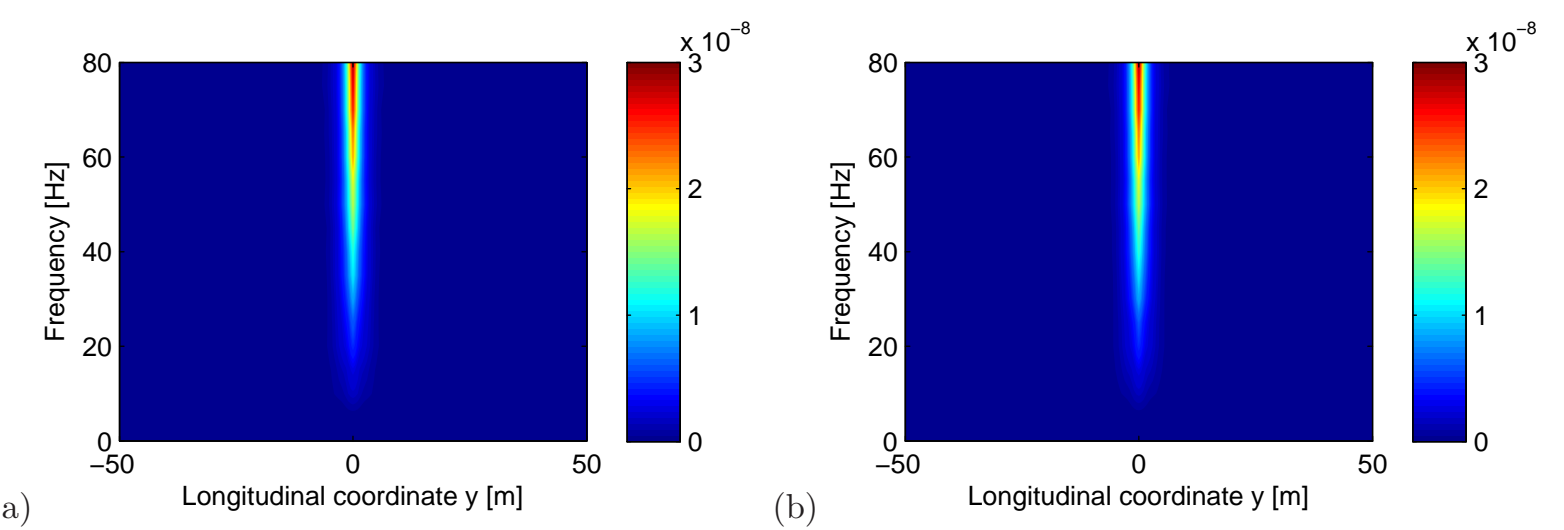

Figure 8: Mean power flow per unit length through the tunnel-soil interface due to vertical harmonic excitation in the tunnel at $\mathbf{x}=\left\{0 \mathrm{~m}, 0 \mathrm{~m},-D_{\mathrm{t}}-d_{\mathrm{t}} / 2+t_{\mathrm{t}}\right\}^{\mathrm{T}}$, calculated with the (a) uncoupled and (b) coupled approach. The tunnel is embedded in a soft soil and situated at a depth $D_{\mathrm{t}}=5 \mathrm{~m}$ below the free surface.

Figure 9 shows the mean power flow per unit length through the soil-foundation interface of the middle strip foundation as a function of the longitudinal coordinate and the frequency. Positive values indicate the transmission of energy from the soil into the foundations. Results obtained with the uncoupled and coupled approach are compared, revealing that through-soil coupling of source and receiver moderately affects the power flow distribution through the soil-foundation interfaces at low frequencies. Source-receiver interaction has only a minor influence at higher frequencies, however.

\subsection{Parametric study}

The power flow approach can now be employed to assess the significance of source-receiver interaction for different tunnel depths and soil types. Figure 10 shows the $\widehat{\mathrm{PFIG}}(\omega)$ in a frequency range from $0 \mathrm{~Hz}$ to $80 \mathrm{~Hz}$ for tunnel depths $D_{\mathrm{t}}$ varying from $5 \mathrm{~m}$ to $25 \mathrm{~m}$, and for the three soil types outlined in table 1 . The minimal distance between the tunnel roof and the strip foundations is denoted as $\mathscr{D}=D_{\mathrm{t}}-d_{\mathrm{t}} / 2-h_{\mathrm{sf}}$. It is often assumed in seismic engineering that source-receiver interaction can be neglected if the distance between source and receiver is sufficiently large compared to the wavelength of waves in the soil [15, 16]. This intuitive idea is assessed in figure 10 by superimposing lines at which the distance $\mathscr{D}$ equals the dilatational 

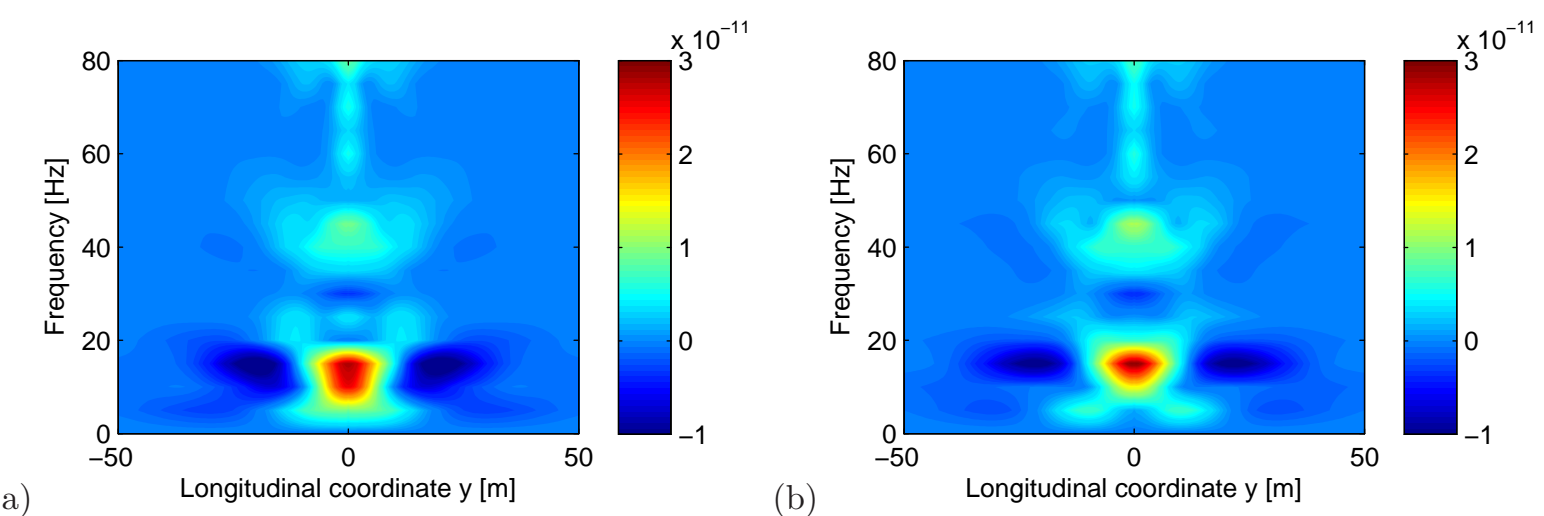

Figure 9: Mean power flow per unit length through the soil-foundation interface of the middle strip foundation due to vertical harmonic excitation in the tunnel at $\mathbf{x}=\left\{0 \mathrm{~m}, 0 \mathrm{~m},-D_{\mathrm{t}}-d_{\mathrm{t}} / 2+t_{\mathrm{t}}\right\}^{\mathrm{T}}$, calculated with the (a) uncoupled and (b) coupled approach. The tunnel is embedded in a soft soil and situated at a depth $D_{\mathrm{t}}=5 \mathrm{~m}$ below the free surface.

wavelength $\lambda_{\mathrm{p}}$ in the soil, i.e. $\omega=2 \pi C_{\mathrm{p}} / \mathscr{D}$. The $\widehat{\mathrm{PFIG}}(\omega)$ tends to $0 \mathrm{~dB}$ above these lines, indicating that the uncoupled approach indeed yields the same result as the coupled approach if the distance $\mathscr{D}$ between source and receiver is larger than the dilatational wavelength $\lambda_{\mathrm{p}}$. An increasing deviation up to $\pm 2 \mathrm{~dB}$ between the coupled and uncoupled approach can be observed below the lines, as the distance $\mathscr{D}$ is smaller than the wavelength $\lambda_{\mathrm{p}}$. The uncoupling does, however, not systematically result in an under- or overestimation of the total mean power entering the building; this strongly depends on the tunnel depth, the soil type and the frequency considered. Although the different regions in the contour plots are not very sharply delimited, these results nevertheless suggest that the rule of thumb commonly applied in seismic engineering also applies to the prediction of railway induced vibrations.

The influence of source-receiver interaction is also investigated for an alternative foundation design. Figure $2 \mathrm{~b}$ shows the four storey portal frame founded on a box foundation (subscript 'bf') with width $w_{\mathrm{bf}}=12 \mathrm{~m}$, height $h_{\mathrm{bf}}=1 \mathrm{~m}$ and thickness $t_{\mathrm{bf}}=0.30 \mathrm{~m}$; the soil-foundation interface is thus larger than for the strip foundations previously considered. The same material properties as for the strip foundations are used. The total mean power flowing into the building in case of harmonic excitation at $\mathbf{x}=\left\{0 \mathrm{~m}, 0 \mathrm{~m},-D_{\mathrm{t}}-\right.$ $\left.d_{\mathrm{t}} / 2+t_{\mathrm{t}}\right\}^{\mathrm{T}}$ of a tunnel embedded in a soft soil situated at a depth $D_{\mathrm{t}}=5 \mathrm{~m}$ is shown in figure $11 \mathrm{~b}$. The net power input is up to $8 \mathrm{~dB}$ higher than in the case where the building on embedded strip foundations is considered (figure 11a). Figure 11b indicates, however, that the significance of through-soil coupling also remains limited to $\pm 2 \mathrm{~dB}$ in the case of a box foundation, although the effect is slightly more pronounced than in case of embedded strip foundations.

The observed deviations of $\pm 2 \mathrm{~dB}$ are relatively small compared to other sources of uncertainty, such as small variations of soil characteristics [9, 10, 48], the interaction between neighbouring tunnels [13], or the presence of voids at the tunnel-soil interface [14]. This suggests that accounting for source-receiver interaction does not significantly improve the accuracy of vibration predictions. Nevertheless, if insertion gains $\widehat{\mathrm{IG}}_{i}(\mathbf{x}, \omega)$ at particular locations are considered, the source-receiver interaction effects can easily reach $10 \mathrm{~dB}$ in the frequency range of interest. This is of the same order of magnitude as other sources of uncertainty; this should be beared in mind when performing vibration predictions.

\section{Dynamic interaction between a railway track at grade and a building}

\subsection{Case description}

In this section, a conventional ballasted railway track at the surface of the halfspace is considered, as shown in figure 12. $D_{\mathrm{t}}$ indicates the distance between the centre of the track and the right wall of the building. The track consists of UIC 60 rails supported by rail pads on concrete sleepers, which are founded on a ballast layer. The rails are modelled as Euler-Bernoulli beams with a bending stiffness $E_{\mathrm{r}} I_{\mathrm{r}}=6.4 \times 10^{6} \mathrm{Nm}^{2}$ and 

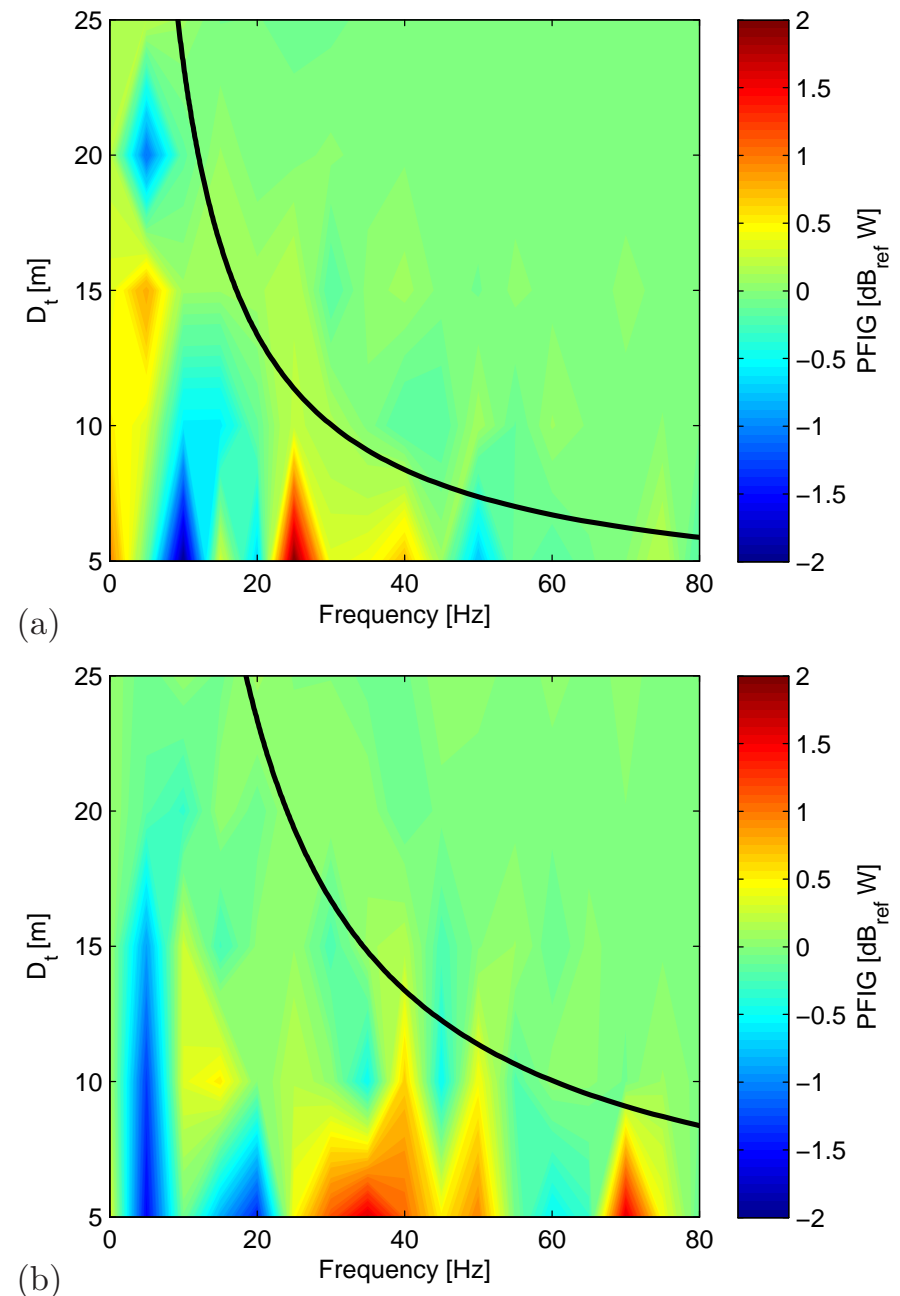

(b)

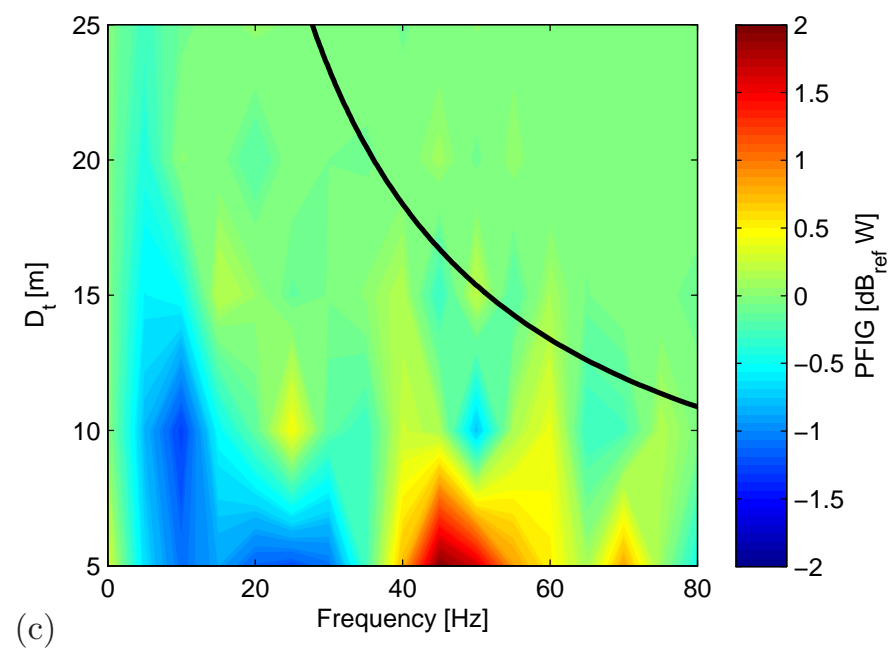

Figure 10: Power flow insertion gain $\widehat{\mathrm{PFIG}}(\omega)$ for a building founded on three embedded strip foundations in case of a (a) soft, (b) medium, and (c) stiff soil. The tunnel depth $D_{\mathrm{t}}$ varies from $5 \mathrm{~m}$ to $25 \mathrm{~m}$. 

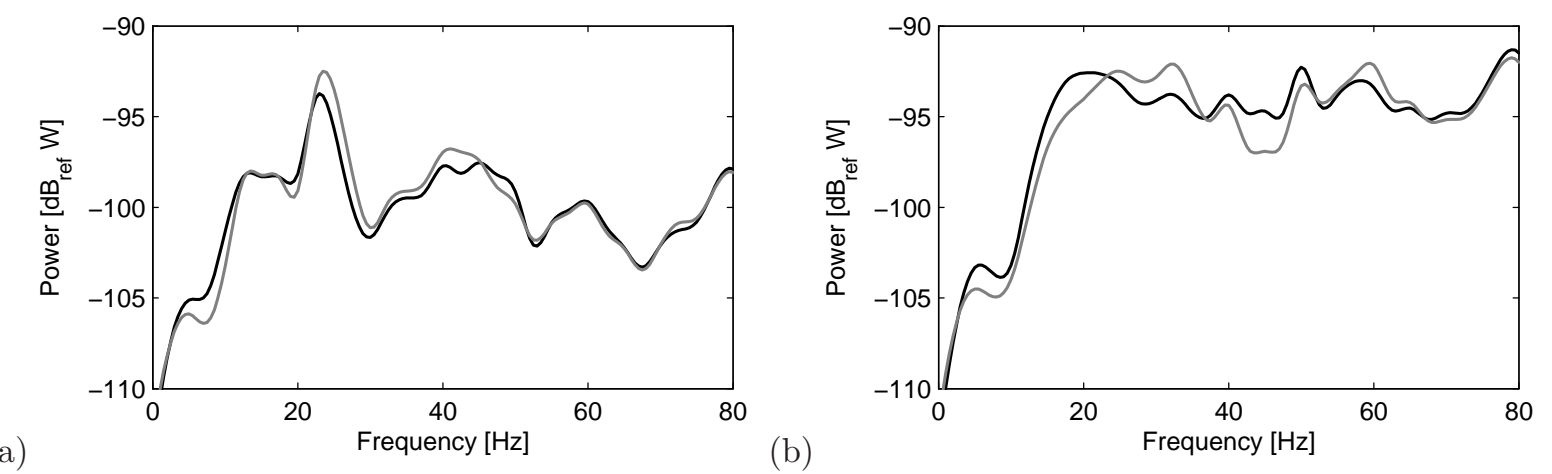

Figure 11: Total mean power flowing into the building founded (a) on three embedded strip foundations and (b) on a box foundation due to vertical harmonic excitation in the tunnel at $\mathbf{x}=\left\{0 \mathrm{~m}, 0 \mathrm{~m},-D_{\mathrm{t}}-d_{\mathrm{t}} / 2+t_{\mathrm{t}}\right\}^{\mathrm{T}}$, calculated with the uncoupled (black line) and coupled (grey line) approach. The tunnel is embedded in a soft soil and situated at a depth $D_{\mathrm{t}}=5 \mathrm{~m}$ below the free surface.

a mass per unit length $\rho_{\mathrm{r}} A_{\mathrm{r}}=60 \mathrm{~kg} / \mathrm{m}$ for each rail. A standard track gauge of $1.435 \mathrm{~m}$ is considered. The rail pads have a stiffness $k_{\mathrm{rp}}=300 \times 10^{6} \mathrm{~N} / \mathrm{m}$ and a damping coefficient $c_{\mathrm{rp}}=3.5 \times 10^{3} \mathrm{Ns} / \mathrm{m}$. The following sleeper characteristics are considered: a length $l_{\mathrm{sl}}=2.60 \mathrm{~m}$, a width $b_{\mathrm{sl}}=0.25 \mathrm{~m}$, a height $h_{\mathrm{sl}}=0.20 \mathrm{~m}$ (under the rail), a sleeper distance $d_{\mathrm{sl}}=0.60 \mathrm{~m}$ and a mass $m_{\mathrm{sl}}=325 \mathrm{~kg}$. An equivalent continuous model is employed based on the equivalent rail pad stiffness $\bar{k}_{\mathrm{rp}}=k_{\mathrm{rp}} / d_{\mathrm{sl}}$, damping coefficient $\bar{c}_{\mathrm{rp}}=c_{\mathrm{rp}} / d_{\mathrm{sl}}$ and uniformly distributed sleeper mass $\bar{m}_{\mathrm{sl}}=m_{\mathrm{sl}} / d_{\mathrm{sl}}$ per unit length. The ballast layer has a thickness $t=0.30 \mathrm{~m}$ and a width $w_{\mathrm{t}}$ varying linearly with depth from $3.60 \mathrm{~m}$ under the sleepers to $5.60 \mathrm{~m}$ at the track-soil interface. The ballast is characterized by a shear wave velocity $C_{\mathrm{s}}=300 \mathrm{~m} / \mathrm{s}$, a dilatational wave velocity $C_{\mathrm{p}}=600 \mathrm{~m} / \mathrm{s}$, a density $\rho=2000 \mathrm{~kg} / \mathrm{m}^{3}$ and a material damping ratio $\beta_{\mathrm{s}}=\beta_{\mathrm{p}}=0.020$ in both deviatoric and volumetric deformation.

The same building as introduced in section 3 is considered at the receiver side (i.e. a four storey portal frame founded on embedded strip foundations), while all three soil types summarized in table 1 are investigated. The source consists of a unit harmonic vertical point load applied to the left rail at $y=0 \mathrm{~m}$.

\subsection{Numerical results}

It is first verified whether the track compliance $\hat{\mathbf{C}}^{\mathrm{tr}}(\omega)$ (and the generation of dynamic axle loads $\hat{\mathbf{g}}(\omega)$ ) is affected by source-receiver interaction. Figure 13 shows the rail receptance $\hat{u}_{\mathrm{r}}(y=0 \mathrm{~m}, \omega)$ for a railway track on a soft soil (table 1 ) and aligned along $x=15 \mathrm{~m}$ (figure 12); the distance $D_{\mathrm{t}}$ thus equals $9 \mathrm{~m}$. It is clearly illustrated that the rail receptance is not modified by disregarding the presence of the building, suggesting that an uncoupled calculation suffices for the determination of the dynamic axle loads. Discretization of the track results in $1473 \mathrm{FE}$ and $267 \mathrm{BE}$ DOFs. An uncoupled calculation takes 4.6 min per frequency, while $11.5 \mathrm{~min}$ per frequency is required if source-receiver interaction is accounted for (after parallelization of the wavenumber domain computations).

Next, the transfer functions from track to building are investigated. Large spatial and directional variation is observed if source-receiver interaction is quantified through the insertion gain $\widehat{\mathrm{IG}}_{i}(\mathbf{x}, \omega)$ as defined in equation (12). This is illustrated in figure 14 , which shows insertion gains $\widehat{\mathrm{IG}}_{i}(\mathbf{x}, \omega)$ for locations $\mathbf{x}$ corresponding to a grid of points located on the first floor of the four storey portal frame, within a range from $y=-10 \mathrm{~m}$ to $y=+10 \mathrm{~m}$. The power flow concept introduced in subsection 3.3 is applied to this case study as well in order to obtain a global assessment of the interaction effects.

Figure 15 shows the $\widehat{\operatorname{PFIG}}(\omega)$ in a frequency range from $0 \mathrm{~Hz}$ to $80 \mathrm{~Hz}$ for a distance $D_{\mathrm{t}}$ between the track and the building varying from $9 \mathrm{~m}$ to $29 \mathrm{~m}$ (i.e. for tracks aligned from $x=15 \mathrm{~m}$ to $x=35 \mathrm{~m}$ ), and for the three soil types outlined in table 1. The minimal distance between the track and the strip foundations is denoted as $\mathscr{D}=D_{\mathrm{t}}-w_{\mathrm{t}} / 2-w_{\mathrm{sf}} / 2$. It can be expected that source-receiver interaction is unimportant if the Rayleigh wavelength $\lambda_{\mathrm{R}}$ in the soil is very small compared to the source-receiver distance $\mathscr{D}$. Lines satisfying the relation $\omega=6 \times 2 \pi C_{\mathrm{R}} / \mathscr{D}$ (corresponding to frequencies at which the distance $\mathscr{D}$ is equal 


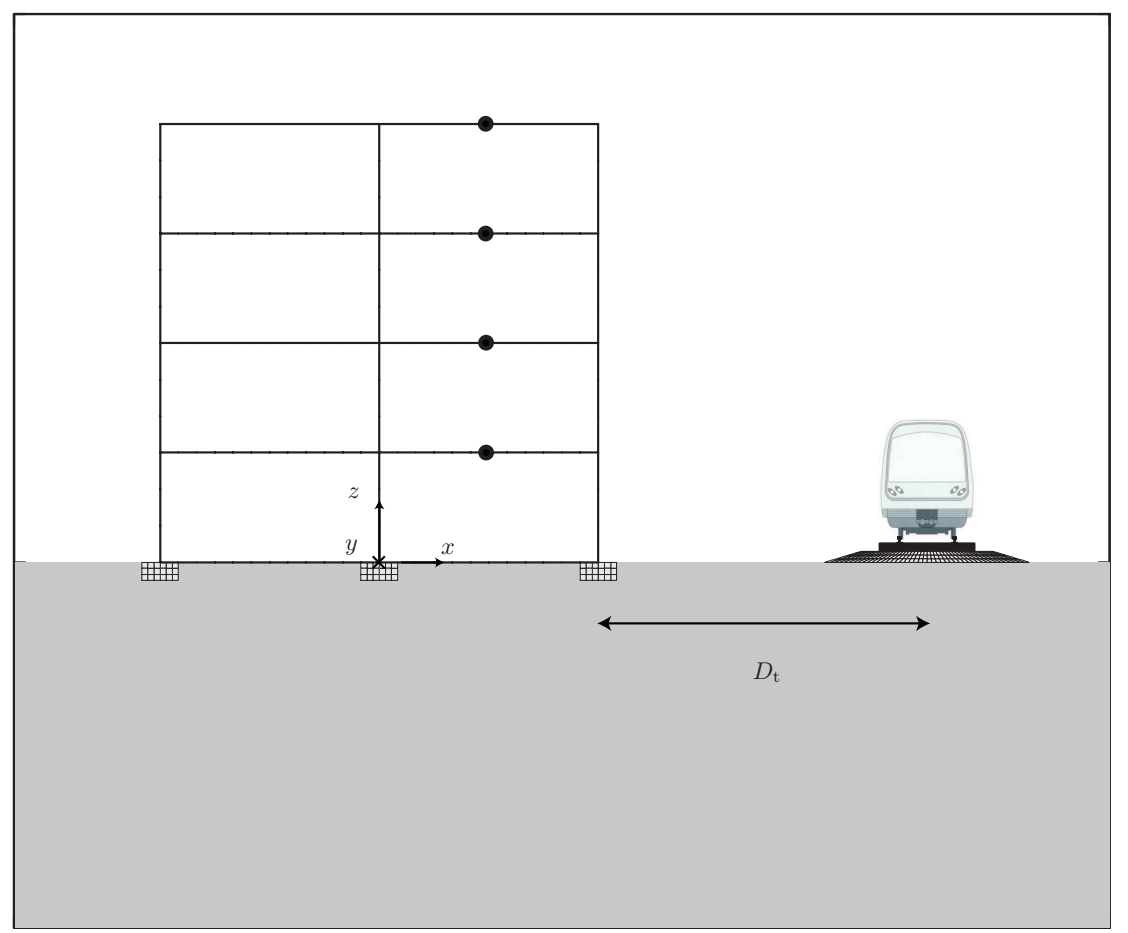

Figure 12: Railway track situated at a distance $D_{\mathrm{t}}$ from a four storey portal frame founded on three embedded strip foundations. Vibrations during the passage of a freight train are evaluated at the locations indicated by a dot.
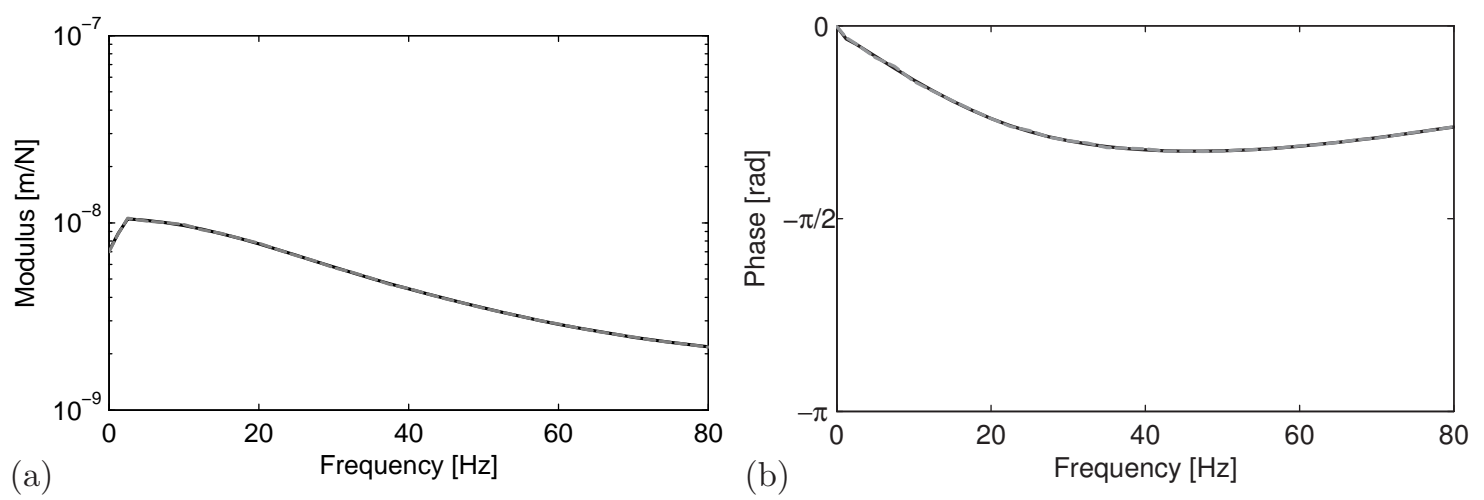

Figure 13: (a) Modulus and (b) phase of the rail receptance $\hat{u}_{\mathrm{r}}(y=0 \mathrm{~m}, \omega)$ due to vertical harmonic excitation of the rail for a railway track on a soft soil situated at a distance $D_{\mathrm{t}}=9 \mathrm{~m}$ from the building, calculated with the uncoupled (solid black line) and coupled (dashed grey line) approach.

to six Rayleigh wavelengths $\lambda_{\mathrm{R}}$ ) are superimposed on figure 15, and it can indeed be observed that the $\widehat{\mathrm{PFIG}}(\omega)$ tends to $0 \mathrm{~dB}$ outside the region bounded by these lines. Through-soil coupling of source and receiver affects the power flow input slightly if the Rayleigh wavelength is of the some order of magnitude as the distance $\mathscr{D}$. This differs from the observation in subsection 3.4 with a source located at depth, where interaction effects are observed if the dimensionless distance $\mathscr{D} / \lambda_{\mathrm{p}}$ becomes smaller than one. No clear trend in the deviation between the coupled and uncoupled approach is apparent in figure 15, however. Moreover, the overall influence of through-soil coupling remains situated between $-1 \mathrm{~dB}$ and $+0.5 \mathrm{~dB}$, suggesting that source-receiver interaction only plays a negligible roll on the transfer from source to receiver. 

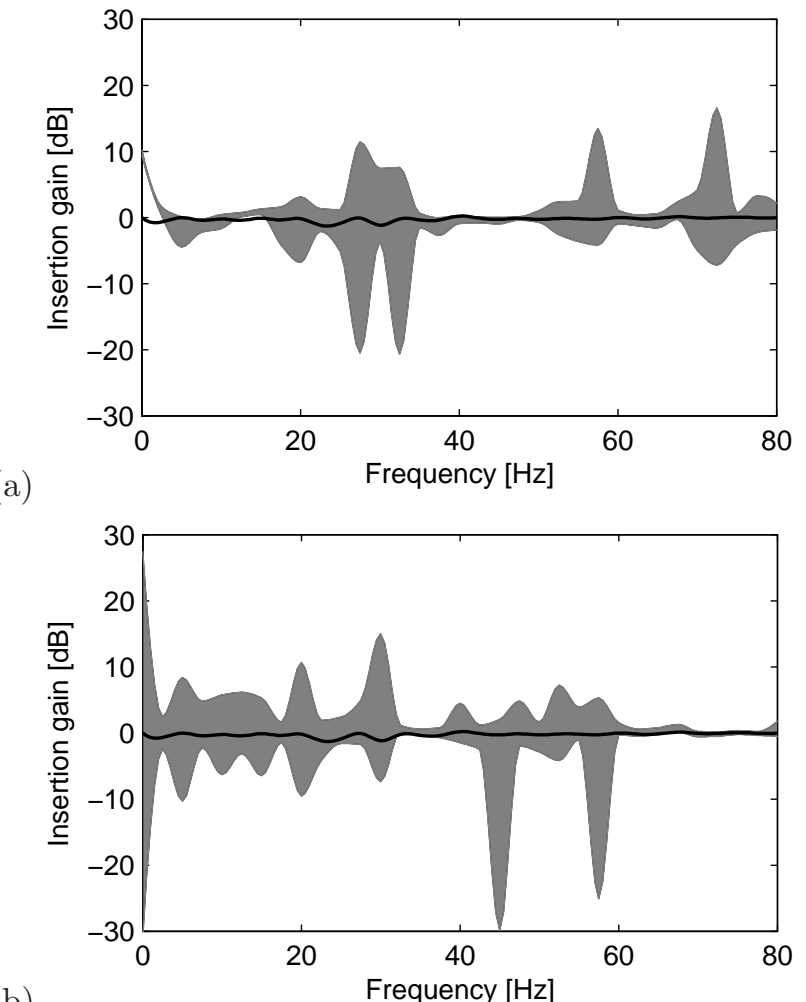

(b)

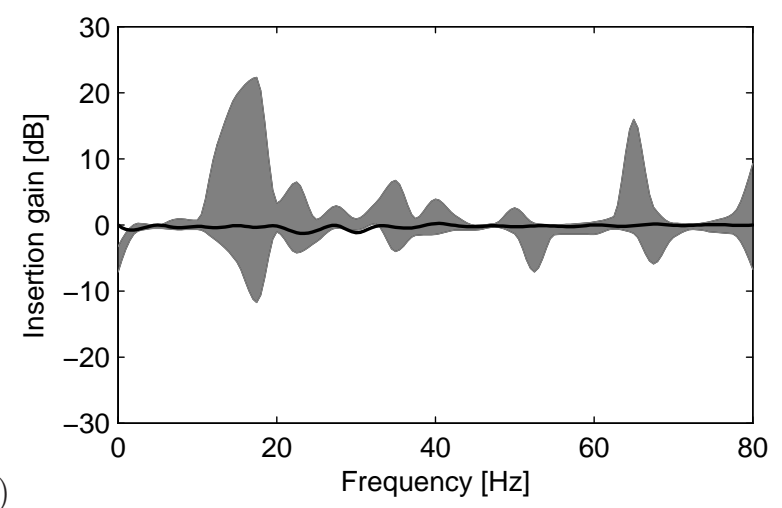

Figure 14: Vibration insertion gains (a) $\widehat{\mathrm{IG}}_{x}(\mathbf{x}, \omega)$, (b) $\widehat{\mathrm{IG}}_{y}(\mathbf{x}, \omega)$ and (c) $\widehat{\mathrm{IG}}_{z}(\mathbf{x}, \omega)$ on the first floor of the four storey portal frame founded on three embedded strip foundations in a range $y \in[-10 \mathrm{~m}, 10 \mathrm{~m}]$ (grey patch). Superimposed is the power flow insertion gain $\widehat{\mathrm{PFIG}}(\omega)$ (black line). 

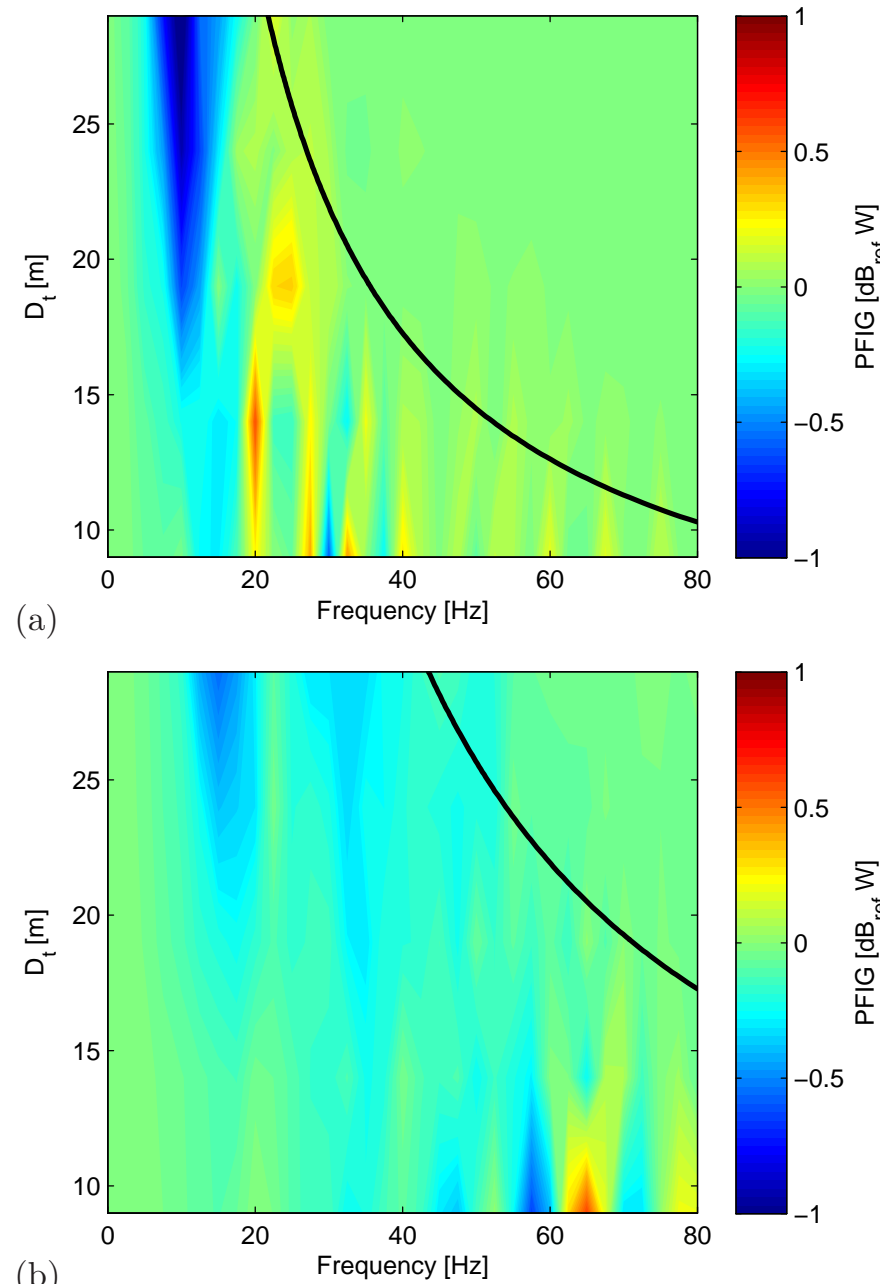

(b)

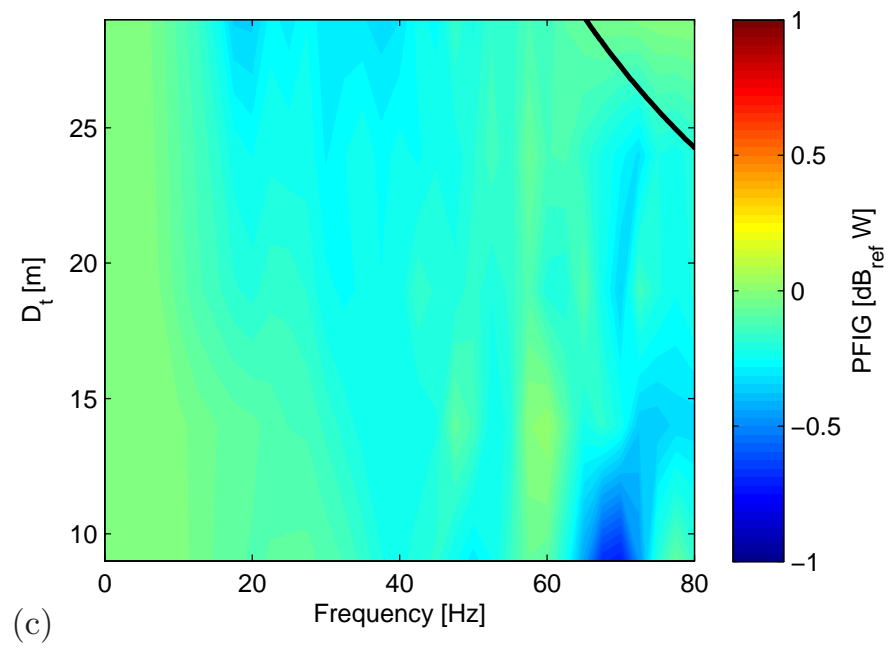

Figure 15: Power flow insertion gain $\widehat{\mathrm{PFIG}}(\omega)$ for a building founded on three embedded strip foundations in case of a (a) soft, (b) medium, and (c) stiff soil. The distance $D_{\mathrm{t}}$ between track and building varies from $9 \mathrm{~m}$ to $29 \mathrm{~m}$. 


\subsection{Passage of a freight train}

A comprehensive case study of the passage of a freight train on the railway track on the surface of a medium soil is finally considered; both the coupled and uncoupled models are employed. The distance $D_{\mathrm{t}}$ between the building and the track equals $9 \mathrm{~m}$ (figure 12). The freight train has a speed $v=80 \mathrm{~km} / \mathrm{h}$ and is composed of two traction cars BB 22200, six Rilmms-R00 wagons, and 20 Sgss-S06 wagons [49]. The number of axles $N_{\mathrm{a}}$, the carriage length $L_{\mathrm{t}}$, the distance $L_{\mathrm{b}}$ between bogies, the axle distance $L_{\mathrm{a}}$, and the unsprung axle mass $M_{\mathrm{u}}$ of the carriages are summarized in table 4.3. Only these unsprung masses are taken into account in the numerical model.

\begin{tabular}{lccccc}
\hline & $N_{\mathrm{a}}$ & $L_{\mathrm{t}}$ & $L_{\mathrm{b}}$ & $L_{\mathrm{a}}$ & $M_{\mathrm{u}}$ \\
{$[-]$} & {$[\mathrm{m}]$} & {$[\mathrm{m}]$} & $\begin{array}{c}{[\mathrm{m}]} \\
{[\mathrm{kg}]}\end{array}$ \\
\hline Traction car BB 22200 (2) & 4 & 17.48 & 9.69 & 2.80 & 3130 \\
Rilmms-R00 wagon (6) & 4 & 14.04 & 9.00 & 1.80 & 1225 \\
Sgss-S06 wagon (20) & 4 & 20.64 & 15.60 & 1.80 & 1225 \\
\hline
\end{tabular}

Table 2: Characteristics of the freight train.

Dynamic axle loads $\hat{\mathbf{g}}(\omega)$ originating from the track unevenness $\hat{\mathbf{u}}_{\mathrm{w} / \mathrm{r}}(\omega)$ are considered, assuming a track with an unevenness profile according to the FRA class 3 [50]; the latter corresponds to a track of moderate quality. The response due to a train passage is characterized by an increasing vibration level when the train is approaching, a nearly stationary vibration level during the passage of the train and a decreasing vibration level when the train moves away. It has been shown that the stationary part of the response can be well approximated assuming that the dynamic axle loads are applied at fixed positions [51]; this assumption is especially appropriate in case of long trains at a relatively low speed. This approach is therefore employed in this case study.

Figure 16 shows the one-third octave band RMS spectra of the first axle load $\hat{\mathbf{g}}_{1}(\omega)$ of the freight train, calculated with the uncoupled and coupled approach, respectively. Both curves coincide, indicating that the presence of the building can be disregarded for a correct estimation of the dynamic axle loads.

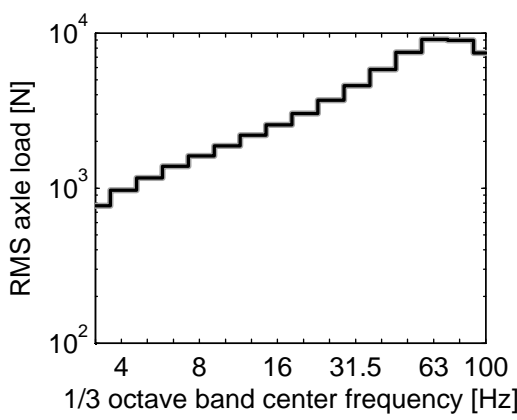

Figure 16: One-third octave band RMS spectra of the first axle load $\hat{\mathbf{g}}_{1}(\omega)$ of the freight train at a speed of $80 \mathrm{~km} / \mathrm{h}$, calculated with the uncoupled (black line) and coupled (grey line) approach. The railway track is situated at a distance $D_{\mathrm{t}}=9 \mathrm{~m}$ from the building.

Figure 17 shows the one-third octave band RMS spectra of the horizontal and vertical vibration velocity at the mid-spans of the four floors on the right-hand side of the building (as indicated on figure 12). A reasonable agreement between the uncoupled and coupled approach is obtained up to $\pm 30 \mathrm{~Hz}$. This frequency approximately corresponds to the frequency at which the distance $\mathscr{D}=D_{\mathrm{t}}-w_{\mathrm{t}} / 2-w_{\mathrm{sf}} / 2$ between the track and the strip foundations equals one Rayleigh wavelength $\lambda_{\mathrm{R}}$ in the soil, i.e. $f=C_{\mathrm{R}} / \mathscr{D}=$ $32.6 \mathrm{~Hz}$. The difference between the results is considerably larger at higher frequencies, however, indicating that discrepancies between the coupled and uncoupled approach mainly arise if the Rayleigh wavelength is comparable to the distance between source and receiver. As a train passage is considered (combining 
transfer functions from several axle positions to the building), the spatial variability of individual transfer functions due to source-receiver interaction is much less pronounced. Furthermore, small frequency shifts of these transfer functions are less apparent due to the presentation of the results in one-third octave bands. As a result, the one-third octave band RMS spectra of the vibration velocities exhibit the same tendency as the power flow insertion gain $\widehat{\operatorname{PFIG}}(\omega)$ (figure 15).

\section{Conclusions}

The numerical prediction of vibrations in buildings due to railway traffic is a complicated problem where wave propagation in the soil couples the source and the receiver. In this paper, it has been investigated to which extent disregarding dynamic through-soil coupling of source and receiver affects the accuracy of numerical vibration predictions; the generation of the dynamic axle loads as well as the transfer from source to receiver have been considered. Two case studies have been addressed, considering a railway tunnel at depth and a ballasted track at the surface of a homogeneous halfspace, respectively.

It has been demonstrated that source-receiver interaction does not significantly affect the track compliance, which implies that the dynamic axle loads can be calculated with reasonable accuracy using an uncoupled strategy in which through-soil coupling is neglected. This has been explicitly verified for the passage of a freight train on a ballasted track. If the transfer functions from source to receiver are considered, however, significant local variations up to $10 \mathrm{~dB}$ in terms of pointwise vibration insertion gain are observed, showing a large spatial and directional variability. The overall wave field, however, is only modestly affected by the interaction as shown by a global comparison in terms of the mean vibrational energy entering a building. The case study involving a railway tunnel has illustrated that the interaction between a source at depth and a receiver only affects the power flow distribution if the dimensionless source-receiver distance $\mathscr{D} / \lambda_{\mathrm{p}}$ is smaller than one. This observation is in line with the rule of thumb commonly applied in seismic engineering. For a railway track at grade, interaction effects are observed for a dimensionless source-receiver distance $\mathscr{D} / \lambda_{\mathrm{R}}$ smaller than six. The identified global deviations of $\pm 2 \mathrm{~dB}$ (in terms of power flow insertion gain) represent a relatively small margin. A similar tendency is revealed if the passage of a freight train is considered, but the insertion gain at particular locations can easily reach $10 \mathrm{~dB}$. This is of the same order of magnitude as other sources of uncertainty described in the literature; this should hence be taken into account when performing vibration predictions.

\section{Acknowledgements}

The first author is a doctoral fellow of the Research Foundation Flanders (FWO). The financial support is gratefully acknowledged.

\section{References}

[1] G. Lombaert, G. Degrande, J. Kogut, S. François, The experimental validation of a numerical model for the prediction of railway induced vibrations, Journal of Sound and Vibration 297 (3-5) (2006) 512-535.

[2] A. Kaynia, C. Madshus, P. Zackrisson, Ground vibration from high speed trains: prediction and countermeasure, Journal of Geotechnical and Geoenvironmental Engineering, Proceedings of the ASCE 126 (6) (2000) 531-537.

[3] L. Andersen, C. Jones, Coupled boundary and finite element analysis of vibration from railway tunnels - a comparison of two- and three-dimensional models, Journal of Sound and Vibration 293 (3-5) (2006) 611-625.

[4] J. Forrest, H. Hunt, A three-dimensional tunnel model for calculation of train-induced ground vibration, Journal of Sound and Vibration 294 (2006) 678-705.

[5] H. Hao, T. Ang, Analytical modelling of traffic-induced ground vibrations, Journal of the Engineering Mechanics Division, Proceedings of the ASCE 124 (8) (1998) 921-928.

[6] Y. Yang, H. Hung, Soil vibrations caused by underground moving trains, Journal of Geotechnical and Geoenvironmental Engineering, Proceedings of the ASCE 134 (11) (2008) 1633-1644.

[7] X. Sheng, C. Jones, D. Thompson, Modelling ground vibrations from railways using wavenumber finite- and boundaryelement methods, Proceedings of the Royal Society A - Mathematical, Physical and Engineering Sciences 461 (2005) 2043-2070. 


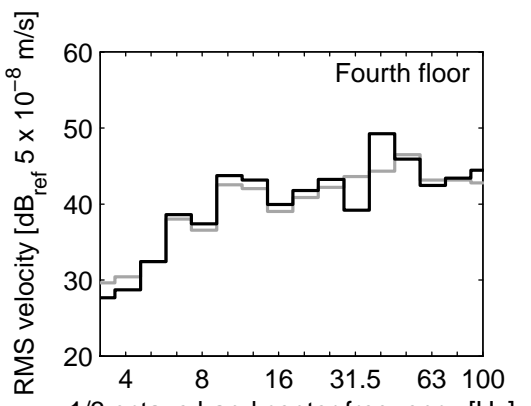

(a)

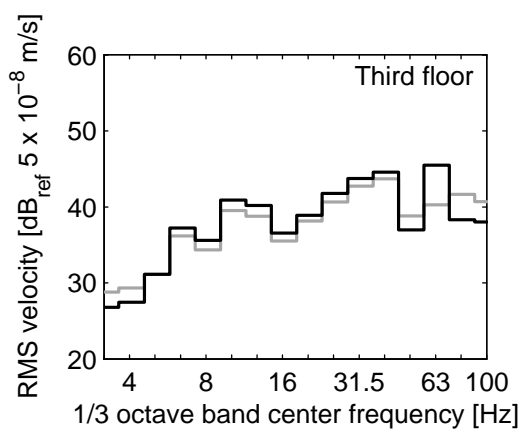

(b)

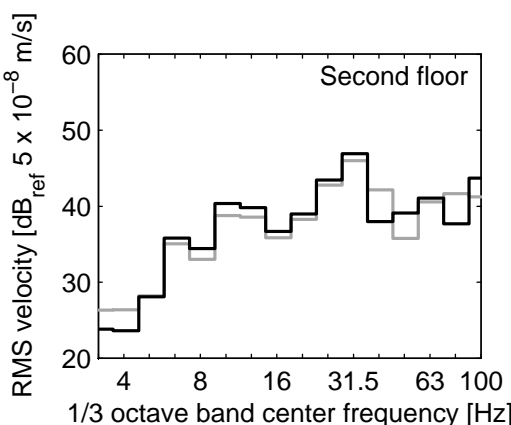

(c)

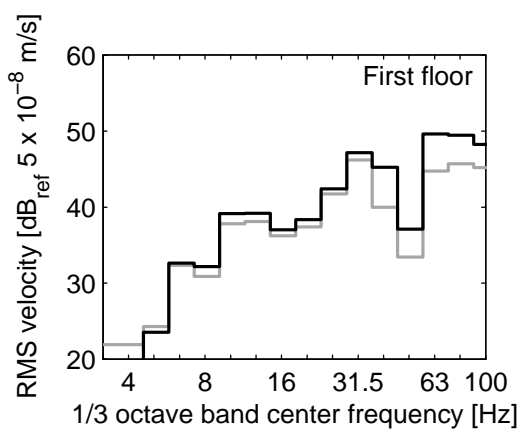

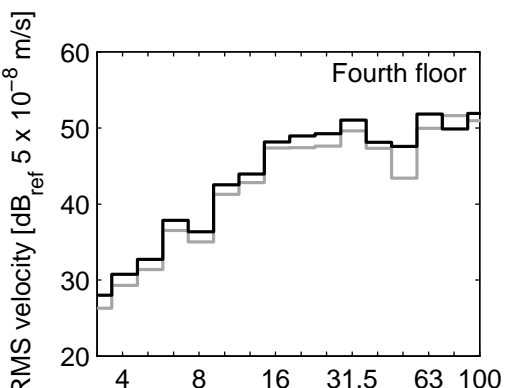

$1 / 3$ octave band center frequency $[\mathrm{Hz}]$

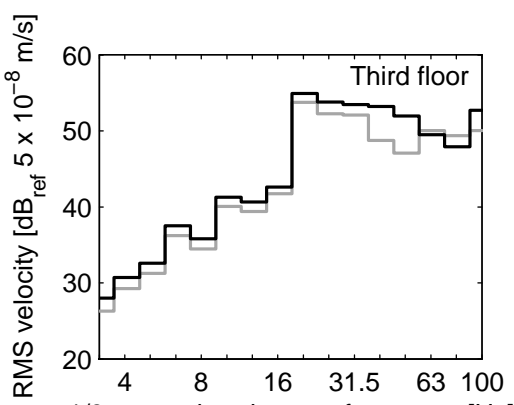

$1 / 3$ octave band center frequency $[\mathrm{Hz}]$

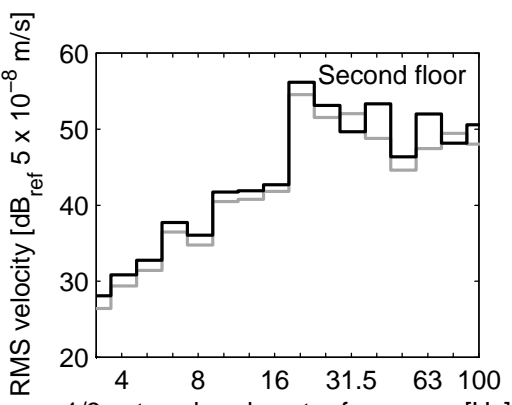

$1 / 3$ octave band center frequency $[\mathrm{Hz}]$

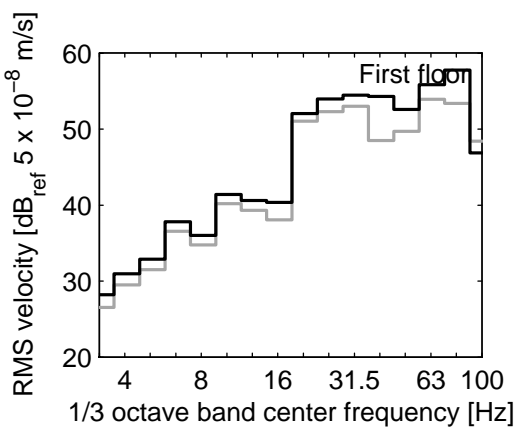

Figure 17: One-third octave band RMS spectra of the horizontal velocity $i \omega \hat{u}_{x}(\mathbf{x}, \omega)$ (left) and the vertical velocity $i \omega \hat{u}_{z}(\mathbf{x}, \omega)$ (right) at the (a) fourth, (b) third, (c) second, and (d) first floor of the four storey portal frame during to the passage of a freight train at a speed of $80 \mathrm{~km} / \mathrm{h}$, calculated with the uncoupled (black line) and coupled (grey line) approach. The railway track is situated at a distance $D_{\mathrm{t}}=9 \mathrm{~m}$ from the building. 
[8] S. François, M. Schevenels, G. Lombaert, P. Galvín, G. Degrande, A 2.5D coupled FE-BE methodology for the dynamic interaction between longitudinally invariant structures and a layered halfspace, Computer Methods in Applied Mechanics and Engineering 199 (23-24) (2010) 1536-1548.

[9] S. Jones, H. Hunt, The effect of inclined soil layers on surface vibration from underground railways using the thin layer method, ASCE Journal of Engineering Mechanics 137 (12) (2011) 887-900.

[10] S. Jones, H. Hunt, Predicting surface vibration from underground railways through inhomogeneous soil, Journal of Sound and Vibration 331 (9) (2012) 2055-2069.

[11] P. Costa, R. Calçada, A. Cardoso, A. Bodare, Influence of soil non-linearity on the dynamic response of high-speed railway tracks, Soil Dynamics and Earthquake Engineering 30 (4) (2010) 221-235.

[12] M. Esmaeili, J. Zakeri, S. Mosayebi, Effect of sand-fouled ballast on train-induced vibration, International Journal of Pavement Engineering. http://dx.doi.org/10.1080/10298436.2013.818146

[13] K. Kuo, H. Hunt, M. Hussein, The effect of a twin tunnel on the propagation of ground-borne vibration from an underground railway, Journal of Sound and Vibration 330 (25) (2011) 6203-6222.

[14] S. Jones, H. Hunt, Voids at the tunnel-soil interface for calculation of ground vibration from underground railways, Journal of Sound and Vibration 330 (2) (2011) 245-270.

[15] J. Bielak, K. Loukakis, Y. Hisada, C. Yoshimura, Domain reduction method for three-dimensional earthquake modeling in localized regions, Part I: Theory, Bulletin of the Seismological Society of America 93 (2) (2003) 817-824.

[16] C. Yoshimura, J. Bielak, Y. Hisada, A. Fernández, Domain reduction method for three-dimensional earthquake modeling in localized regions, Part II: Verification and applications, Bulletin of the Seismological Society of America 93 (2) (2003) $825-840$.

[17] J. Qian, D. Beskos, Harmonic wave response of two 3-D rigid surface foundations, Soil Dynamics and Earthquake Engineering 15 (1996) 95-110.

[18] J. Mulliken, D. Karabalis, Discrete model for dynamic through-the-soil coupling of 3-D foundations and structures, Earthquake Engineering and Structural Dynamics 27 (7) (1998) 687-710.

[19] J. Qian, L. Tham, Y. Chueng, Dynamic cross-interaction between flexible surface footings by combined BEM and FEM, Soil Dynamics and Earthquake Engineering 25 (1996) 509-526.

[20] L. Tham, J. Qian, Y. Cheung, Dynamic response of a group of flexible foundations to incident seismic waves, Soil Dynamics and Earthquake Engineering 17 (1998) 127-137.

[21] L. Padrón, J. Aznárez, O. Maeso, 3-D boundary element - finite element method for the dynamic analysis of piled buildings, Engineering Analysis with Boundary Elements 35 (2011) 465-477.

[22] D. Clouteau, D. Aubry, Modification of the ground motion in dense urban areas, Journal of Computational Acoustics 9 (4) (2001) 1659-1675.

[23] M. Kham, J.-F. Semblat, P.-Y. Bard, P. Dangla, Seismic city-site interaction: main governing phemomena through simplified numerical models, Bulletin of the Seismological Society of America 96 (5) (2006) 1934-1951.

[24] G. Lombaert, D. Clouteau, The resonant multiple wave scattering in the seismic response of a city, Waves in Random and Complex Media 16 (3) (2006) 205-230.

[25] L. Menglin, W. Huaifeng, C. Xi, Z. Yongmei, Structure-soil-structure interaction: Literature review, Soil Dynamics and Earthquake Engineering 31 (12) (2011) 1724-1731.

[26] M. Stupazzini, R. Paolucci, Ground motion induced by train passage in urban area, in: P. Sas, B. Bergen (Eds.), Proceedings of ISMA2010 International Conference on Noise and Vibration Engineering, Leuven, Belgium, 2010, pp. 3547-3558.

[27] L. Schillemans, Impact of sound and vibration of the north-south high-speed railway connection through the city of Antwerp, Belgium, Journal of Sound and Vibration 267 (2003) 637-649.

[28] L. Shi, N. Zhang, The simulation analysis on vibration of a museum building nearby induced by urban subway transit, Advanced Materials Research 243-249 (2011) 3427-3431.

[29] X. Sheng, C. Jones, D. Thompson, A theoretical model for ground vibration from trains generated by vertical track irregularities, Journal of Sound and Vibration 272 (3-5) (2004) 937-965.

[30] S. Gupta, W. Liu, G. Degrande, G. Lombaert, W. Liu, Prediction of vibrations induced by underground railway traffic in Beijing, Journal of Sound and Vibration 310 (2008) 608-630.

[31] L. Filon, On a quadrature formula for trigonometric integrals, Proceedings of the Royal Society of Edinburgh 49 (1929) $38-47$.

[32] M. Heckl, G. Hauck, R. Wettschureck, Structure-borne sound and vibration from rail traffic, Journal of Sound and Vibration 193 (1) (1996) 175-184.

[33] E. Kausel, J. Roësset, Stiffness matrices for layered soils, Bulletin of the Seismological Society of America 71 (6) (1981) $1743-1761$.

[34] M. Schevenels, S. François, G. Degrande, EDT: An ElastoDynamics Toolbox for MATLAB, Computers \& Geosciences 35 (8) (2009) 1752-1754.

[35] M. Bonnet, Boundary integral equation methods for solids and fluids, John Wiley and Sons, Chichester, United Kingdom, 1995 .

[36] H. Schenck, Improved integral formulation for acoustic radiation problems, Journal of the Acoustical Society of America 44 (1968) 41-58.

[37] Z. Ozdemir, P. Coulier, M. Lak, S. François, G. Lombaert, G. Degrande, Numerical evaluation of the dynamic response of pipelines to vibrations induced by the operation of a pavement breaker, Soil Dynamics and Earthquake Engineering 44 (2013) 153-167.

[38] The MathWorks, MATLAB Parallel Computing Toolbox User's Guide (2013).

[39] C. Simmons, Measurement of sound pressure levels at low frequencies in rooms. Comparison of available methods and 
standards with respect to microphone positions, Acta Acustica united with Acustica 85 (1999) 88-100.

[40] R. Langley, Analysis of power flow in beams and frameworks using the direct-dynamic stiffness method, Journal of Sound and Vibration 136 (3) (1990) 439-452.

[41] M. Hussein, H. Hunt, A power flow method for evaluating vibration from underground railways, Journal of Sound and Vibration 293 (3-5) (2006) 667-679.

[42] H. Goyder, R. White, Vibrational power flow from machines into built-up structures, part I: Introduction and approximate analyses of beam and plate-like foundations, Journal of Sound and Vibration 68 (1) (1980) 59-75.

[43] H. Goyder, R. White, Vibrational power flow from machines into built-up structures, part II: Wave propagation and power flow in beam-stiffened plates, Journal of Sound and Vibration 68 (1) (1980) 77-96.

[44] J. Xing, W. Price, A power-flow analysis based on continuum dynamics, Philosophical Transactions of the Royal Society A - Mathematical, Physical and Engineering Sciences 455 (1999) 401-436.

[45] S. Hambric, Power flow and mechanical intensity calculations in structural finite element analysis, Journal of Vibration and Acoustics 112 (1990) 542-549.

[46] Z. Wang, J. Xing, W. Price, An investigation of power flow characteristics of L-shaped plates adopting a substructure approach, Journal of Sound and Vibration 250 (4) (2002) 627-648.

[47] J. Talbot, H. Hunt, A generic model for evaluating the performance of base-isolated buildings, Journal of Low Frequency Noise, Vibration and Active Control 22 (3) (2003) 149-160.

[48] H. Hunt, M. Hussein, Vibration from railways: can we achieve better than +/-10 dB prediction accuracy?, in: 14th International Congress on Sound and Vibration, Cairns, Australia, 2007.

[49] G. Lombaert, P. Galvín, G. Degrande, Prediction of railway induced vibrations at a site in Saint-Epain (France), Tech. Rep. BWM-2009-13, Department of Civil Engineering, KU Leuven (June 2009).

[50] V. Garg, R. Dukkipati, Dynamics of railway vehicle systems, Academic Press, Canada, 1984.

[51] H. Verbraken, G. Lombaert, G. Degrande, Verification of an empirical prediction method for railway induced vibrations by means of numerical simulations, Journal of Sound and Vibration 330 (8) (2011) 1692-1703. 